\title{
Integrated Structural Optimisation of Offshore Wind Turbine Support Structures Based on Finite Element Analysis and Genetic Algorithm
}

\author{
Theo Gentils, Lin Wang, Athanasios Kolios ${ }^{1}$ \\ ${ }^{1}$ Centre for Offshore Renewable Energy Engineering, School of Water, Energy and Environment \\ Cranfield University, Cranfield, MK43 0AL, UK
}

\begin{abstract}
By accounting for almost $25 \%$ of the capital cost of an OWT (offshore wind turbine), optimisation of support structures provides an efficient way to reduce the currently high cost of offshore wind energy. In this paper, a structural optimisation model for OWT support structures has been developed based on a coupled parametric FEA (Finite Element Analysis) and GA (Genetic Algorithm), minimising the mass of the support structure under multi-criteria constraints. Contrary to existing optimisation models for OWT support structures, the proposed model is an integrated structural optimisation model, which optimises the components of the support structure (i.e. tower, transition piece, grout and monopile) simultaneously. The outer diameters and section thicknesses along the support structure are chosen as design variables. A set of constraints based on multi-criteria design assessment is applied according to standard requirements, which includes vibration, stress, deformation, buckling, fatigue and design variable constraints. The model has been applied to the NREL (National Renewable Energy Laboratory) 5MW OWT on an OC3 (Offshore Code Comparison Collaboration) monopile. The results of the application of the integrated optimisation methodology show a $19.8 \%$ reduction in the global mass of the support structure while satisfying all the design constraints. It is demonstrated that the proposed structural optimisation model is capable of effectively and accurately determining the optimal design of OWT support structures, which significantly improves their design efficiency.
\end{abstract}

Keywords: Offshore wind turbine; Support structure; Integrated structural optimisation; Multi-criteria design assessment; Finite element analysis; Genetic algorithm

\begin{tabular}{|llll|}
\hline \multicolumn{2}{l}{ Acronyms } & & \\
DEL & Damage Equivalent Load & NSS & Normal Sea State \\
DLC & Design Load Case & NWM & Normal Wind Model \\
ECM & Extreme Current Model & OC3 & Offshore Code Comparison Collaboration \\
EWM & Extreme Wind Model & OWTs & Offshore Wind Turbines \\
FEA & Finite Element Analysis & PSF & Partial Safety Factor \\
FLS & Fatigue Limit State & RNA & Rotor-Nacelle Assembly \\
GA & Genetic Algorithm & RWH & Reduced Wave Height \\
IEA & International Energy Agency & ULS & Ultimate limit state \\
MSL & Mean Sea Level & 1D & One-dimensional \\
NREL & National Renewable Energy Laboratory & 3D & Three-dimensional \\
\hline
\end{tabular}

\footnotetext{
${ }^{1}$ Corresponding author. Tel.: +44(0)1234 75 4631; E-mail address: a.kolios@cranfield.ac.uk
} 


\begin{tabular}{|c|c|c|c|}
\hline \multicolumn{4}{|c|}{ Nomenclature } \\
\hline$a$ & Amplitude of the wave & $u$ & Horizontal velocity of water particles \\
\hline$c$ & Cohesion value of soil & $\dot{u}$ & Horizontal acceleration of water particles \\
\hline$C_{D}$ & Drag coefficient of the monopile & $u_{c}$ & Current velocity \\
\hline$C_{D, T}$ & Drag coefficient of the tower & $u_{c, M S L}$ & Velocity of current at mean sea level \\
\hline$C_{f}$ & Frictional coefficient between the pile and the soil & $V_{c, e x}$ & Extreme current speed \\
\hline$C_{M}$ & Inertia coefficient of the monopile & $V_{\text {ave }}$ & Annual average wind speed \\
\hline$C_{T}$ & Thrust coefficient of the rotor & $V_{e 50}$ & 50-year extreme wind speed \\
\hline$d_{\text {allow }}$ & Allowable deflection & $V_{g 50}$ & 50 -year extreme $3 \mathrm{~s}$ gust wind speed \\
\hline$d_{\text {pile }}$ & Pile-head deflection & $V_{\text {ref }}$ & Reference wind speed \\
\hline$D$ & External diameter of the tower & $\bar{V}$ & Mean wind velocity \\
\hline$f_{1 P}$ & Rotor induced frequency & $\overline{V_{r}}$ & $\begin{array}{l}\text { Reference wind speed measured at the } \\
\text { nacelle altitude }\end{array}$ \\
\hline$f_{3 P}$ & Blade passing frequency & $x_{1}, x_{2}, \cdots, x_{13}$ & Design variables \\
\hline$f_{1 s t}$ & First natural frequency of the support structure & $x^{L}$ & Lower bound of design variables \\
\hline$f_{\text {sr,allow }}$ & Allowable fatigue safety ratio & $x^{U}$ & Upper bound of design variables \\
\hline$f_{s r, \min }$ & Minimum fatigue safety ratio & $z_{r}$ & Nacelle altitude used as reference height \\
\hline$F_{\text {tower }}$ & Wind loads along the tower & $\alpha$ & Roughness coefficient \\
\hline$F_{h}$ & Hydrostatic force & $\phi$ & Friction angle of soil \\
\hline$F_{o b j}$ & Objective function & $\gamma_{f}$ & $\begin{array}{l}\text { Partial safety factor for consequence of } \\
\text { failure }\end{array}$ \\
\hline$F_{T}$ & Thrust force & $\gamma_{m}$ & Partial safety factor for material \\
\hline$h$ & Local wave depth & $\gamma_{m, f}$ & Material partial safety factor for fatigue \\
\hline$H_{\text {ave }}$ & Average significant wave height & $\eta_{a}$ & Availability of wind turbine \\
\hline$H_{s 50}$ & 50-year extreme significant wave height & $\theta_{\text {allow }}$ & Allowable rotation \\
\hline$k$ & Wave number & $\theta_{i n c}$ & Rotation due to installation incertitude \\
\hline$L_{m}$ & Buckling load multiplier & $\theta_{\text {seabed }}$ & Rotation at the mudline \\
\hline$L_{m, \text { allow }}$ & Allowable buckling load multiplier & $\rho_{a}$ & Air density \\
\hline$M_{\text {global }}$ & Global mass of the support structure & $\rho_{w}$ & Water density \\
\hline$n_{\text {rated }}$ & Rated rotor speed & $\sigma_{f, \text { allow }}$ & Allowable fatigue stress range \\
\hline$N_{I n i}$ & Number of initial samples & $\sigma_{f, d e s i g n}$ & Design fatigue stress range \\
\hline$N_{\text {life }}$ & Design life number of cycles & $\sigma_{T, \text { allow }}$ & Allowable Tresca stress \\
\hline$N_{\text {Maxlter }}$ & Maximum number of iterations & $\sigma_{T, \max }$ & Maximum Tresca stress \\
\hline$N_{\text {PerIni }}$ & Number of samples per iteration & $\sigma_{V M, \text { allow }}$ & Allowable von Mises stress \\
\hline$R$ & Rotor radius & $\sigma_{V M, \text { max }}$ & Maximum von Mises stress \\
\hline$T_{\text {ave }}$ & Average wave period & $\sigma_{y, s}$ & Yield strength of the soil \\
\hline$T_{s 50}$ & 50 -year peak spectral period & $\omega$ & Angular frequency of the wave \\
\hline
\end{tabular}




\section{Introduction}

Since its early development in the 1980s, wind energy has experienced an unprecedented development with more than $1500 \%$ increase in global wind power installation over the last 15 years, reaching a total installed capacity of $432 \mathrm{GW}$ at the end of 2015 [1]. It is considered to be one of the key contributors to satisfying continuous, increasing energy demand and targets for reduced environmental emissions. Given the increasing trend of rotor sizes [2], and since OWTs (offshore wind turbines) benefit from the larger available space, higher wind shear and less variability on market price [3], considerable investments are being deployed in deeper sites located further from shore [4], sharing experience from onshore wind turbines and offshore technologies [5]. Studies have shown that offshore wind could contribute to around $5.5 \%$ of the world's electricity by 2050 [6].

Different types of support structures for OWTs exist, as illustrated in Fig. 1. The choice of types of support structure depends on multiple criteria, such as water depth, seabed conditions and financial constraints [7-11]. Monopiles (see Fig. 1b) are currently the most common foundation concept, representing 80.1\% of total EU's installations in 2015 [12]. Preferred by industry for their simple and robust design, monopiles have been installed in water depths ranging from $5 \mathrm{~m}$ to $30 \mathrm{~m}$. For deeper site locations, monopiles tend to become practically constrained and economically non-competitive [7]. Thus, different concepts such as jacket structures or, most recently, floating support structure are deemed more suitable. This study focuses on monopiles, as they still represent the vast majority of already installed or currently in design OWT support structures.

(a)

(b)

(c)

(d)

(e)

(f)

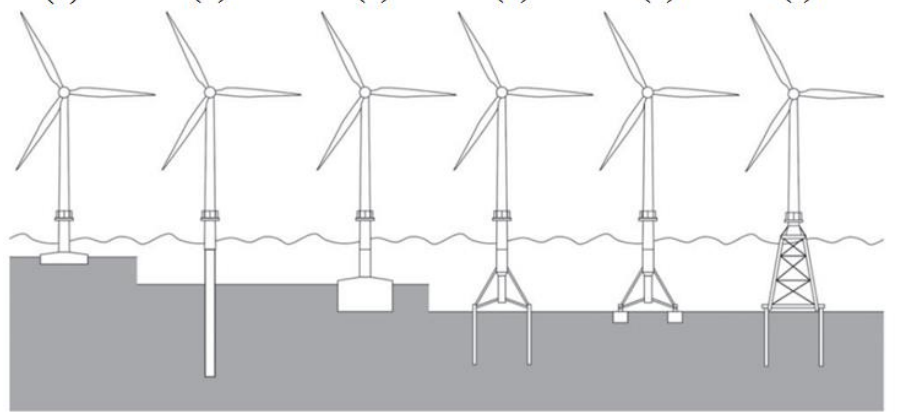

Figure 1. Typical foundation concepts [13]: a gravity-based foundation, $\mathbf{b}$ monopile foundation, $\mathbf{c}$ caisson foundation, d multi-pile foundation, e multi-caisson foundation, $\mathbf{f}$ jacket foundation

In addition to higher costs induced by offshore location, OWT support structures require site-specific design consideration in order to ensure the nominal 20-25 years of operational life. As a consequence, the levelised cost of energy (LCOE) of OWTs in 2013 was reported at 215 \$/MWh, which was more than three times higher than onshore wind turbines [14]. Although the LCOE of OWT has been reduced recently, the contribution of support structures for OWTs still account for $20-25 \%$ of the capital cost [15]. Thus, reducing the support structure cost through structural optimisation is a key enabler to decrease offshore wind costs and make this solution less dependent on subsidy schemes [13]. 
A structural optimisation model of OWT support structures requires two main components, i.e. 1) a structural model which describes the structural behaviour of support structures; and 2) an optimisation algorithm which finds the optimal set of design variable(s), with regard to the objective function(s) and constraint(s).

Structural models used for OWT support structures can be roughly categorised into two groups, i.e. 1D (onedimensional) beam models and 3D (three-dimensional) FEA (finite element analysis) models. A 1D beam model discretises the support structure into a series of elastic Euler or Timoshenko beam elements. Due to its computational efficiency and acceptable accuracy to model global structural dynamics behaviour, the beam model has been widely used in commercial codes (e.g. GH-Bladed [16]) to model OWT support structures. Although efficient, the beam model fails to represent accurately structural responses, such as stress concentration effects, when a more local scale is required [17]. In order to capture structural responses accurately, it is necessary to construct the OWT support structures using 3D FEA. In 3D FEA, the support structures are generally constructed using 3D shell or brick elements. Compared to the 1D beam model, the 3D FEA model is capable of capturing structural responses accurately and examining detailed stress distributions across the structure. Due to its high fidelity, the 3D FEA model has been widely used for modelling wind turbine structures [18-20]. Therefore, the 3D FEA is chosen in this study to model the OWT support structures.

In addition to the support structure, the soil structure interaction should be modelled, as the simplification of assuming a rigid soil could lead to up to $20 \%$ of errors in natural frequencies of the structure [21], which is obviously not acceptable with regard to resonance risk assessment. When considering a flexible soil, foundations are usually designed using the well-known p-y method [22], in which soil is modelled by equivalent springs, with stiffness based on soil property. Nevertheless, this method was designed and validated for Oil and Gas applications only, which does not fit with the larger pile diameters used for OWT monopiles. Consequently, it tends to overestimate the pile-soil stiffness, underestimate lateral deflections [23] and does not depict properly the predominant body motion of the foundation [24]. A recommended approach to obtain reliable and accurate results is to use 3D FEA with brick elements to represent the soil conditions $[23,25]$. To achieve the required accuracy, the 3D FEA model with brick elements is chosen in this study to model the soil.

The optimisation algorithms used for OWT support structures can be roughly categorised into two groups [26, 27], i.e. calculus-based algorithms and meta-heuristic algorithms. The former relies on a gradient calculation of the objective function to find the sensitivity of each design variable. It features rapid convergence and ensures an optimal solution for convex search-space, which explains its popular utilisation [28-30]. Nevertheless, optimisation problems for offshore structures are generally non-convex [31], which makes the calculus-based algorithms less robust and more likely to end in local optima [32]. Thus, a meta-heuristic algorithm is preferred. The meta-heuristic algorithm is defined as an iterative generation process and problem-independent algorithm that uses intelligent strategy, based on stochastic decisions, to explore efficiently the search space in order to find near-optimal global solutions. Most of the search strategies are evolutionary algorithms based on natural process. The Genetic Algorithm (GA), popularised by [33], is the most popular of meta-heuristic algorithms. It tends to reproduce the natural selection process based on the Darwinian theory of evolution, in which a population tends to evolve through selection and generation of fitter individuals. Since it does not require an explicit mathematical formulation of the problem and the calculation of the gradient of objective function, this 
method has been widely employed in complex problems and has proved to be very efficient and robust for hybrid renewable energy system [34], wind turbine layout in wind farms [35], wind turbine composite blades [36] and OWTrelated studies [37-39]. Therefore, the GA is chosen in this study to search for optimal solutions.

Studies have been performed for design optimisation of OWT support structures. Laszio et al. [40] proposed a simplified design procedure for the design of OWT monopile foundations and applied it to the design of foundations for an offshore wind farm. The results indicated that the simplified design procedure could achieve acceptable initial design in an efficient way. Hong et al. [41] proposed a design methodology of lattice towers for OWTs in the ultimate limit state. The structural topologies were specified in terms of the inclination of bracings, tower cross-section geometry and the number of segments along the tower height. The optimal design was searched for according to tower mass and fabrication complexity. Lee et al. [42] studied the structural topology optimisation of the transition piece for an OWT with jacket foundation. Lighter structure was achieved with the structural topology optimisation, demonstrating the topology optimisation can be effective and speeding up the total design cycle. However, these studies consider an independent optimisation of the different components (such as tower, transition piece and monopile) of OWT support structures. Nevertheless, an integrated approach, in which different components are optimised simultaneously, should ensure better optimisation results [43] and more accurately represent the interaction among components.

The combination of FEA and GA for the integrated structural optimisation of OWT support structures has not been reported in the literature. This paper attempts to develop an innovative integrated structural optimisation model of OWT support structures by combining FEA and GA. A parametric FEA model of OWT support structures is developed and validated and then coupled with GA, based on an integrated approach. The structural optimisation model is applied to the NREL $5 \mathrm{MW}$ wind turbine supported on the OC3 monopile to optimise the overall mass of the support structure while satisfying multiple criteria imposed by design standards. It should be clarified that for the purpose of this study support structure means the assembly of the tower, transition piece, monopile and foundation.

This paper is structured as follows. Section 2 describes the reference model. Section 3 presents the design load analysis. Sections 4 and 5 present the parametric FEA and GA respectively, which are then coupled to form the optimisation model in Section 6. Results and discussion are provided in Section 7, followed by conclusions in Section 8.

\section{Reference model: NREL 5 MW on OC3 Monopile}

\subsection{NREL 5MW OWT}

The NREL 5MW OWT [44] was developed by NREL (National Renewable Energy Laboratory) as a reference model to facilitate research and conceptual studies. This design was extrapolated from operating and conceptual machines to provide a typical multi-megawatt OWT. The RNA (Rotor-Nacelle Assembly) is supported by a $77.6 \mathrm{~m}$ tapered tubular tower. Its basic characteristics are summarised in Table 1 and further details can be found in [44]. The location of RNA is defined with respect to the tower-top coordinate system (see Fig. 2), which originates at the centre of the tower top with $\mathrm{x}$ and $\mathrm{z}$ axes pointing downwind and vertically upwards, respectively. 


\begin{tabular}{ll}
\hline Item & Value \\
\hline Rated power [MW] & 5 \\
Number of blades & 3 \\
Rotor diameter [m] & 126 \\
Rated wind speed [m/s] & 11.4 \\
Rated rotor speed [rpm] & 12.1 \\
Rotor-Nacelle Assembly mass [kg] & 350,000 \\
Tower base diameter [m] & 6 \\
Tower base thickness [m] & 0.027 \\
Tower top diameter [m] & 3.87 \\
Tower top thickness [m] & 0.019 \\
Coordinate location of RNA $(x, y, z)[\mathrm{m}]$ & $(0.41,0.00,1.97)$ \\
Moment of Inertia of RNA $(x, y, z)\left[\mathrm{kg}-\mathrm{m}^{2}\right]$ & $(4.37,2.35,2.54) \times 10^{7}$ \\
\hline
\end{tabular}

\subsection{Adapted OC3 Monopile and transition piece}

The OWT is considered to be supported by a monopile support structure, designed during the OC3 (Offshore Code Comparison Collaboration) project for the IEA (International Energy Agency) [45]. The monopile is designed as a $56 \mathrm{~m}$ length tubular pile with constant section, having an outer diameter of $6 \mathrm{~m}$ and a thickness of $60 \mathrm{~mm} ; 36 \mathrm{~m}$ of the monopile are embedded in the soil, and the remaining $20 \mathrm{~m}$ cover the distance from seabed level up to the sea surface. The depth and denomination of each layer along the monopile are depicted in Fig. 2, and further details can be found in Ref. [45]. The original NREL's design has been adapted to represent both transition piece and a typical grouted connection for this OWT size [46]. The tower is supported by a flange connection with the transition piece at $10 \mathrm{~m}$ above the MSL (mean sea level). The transition piece also ensures a smooth diameter transition between the monopile top and the tower base. 


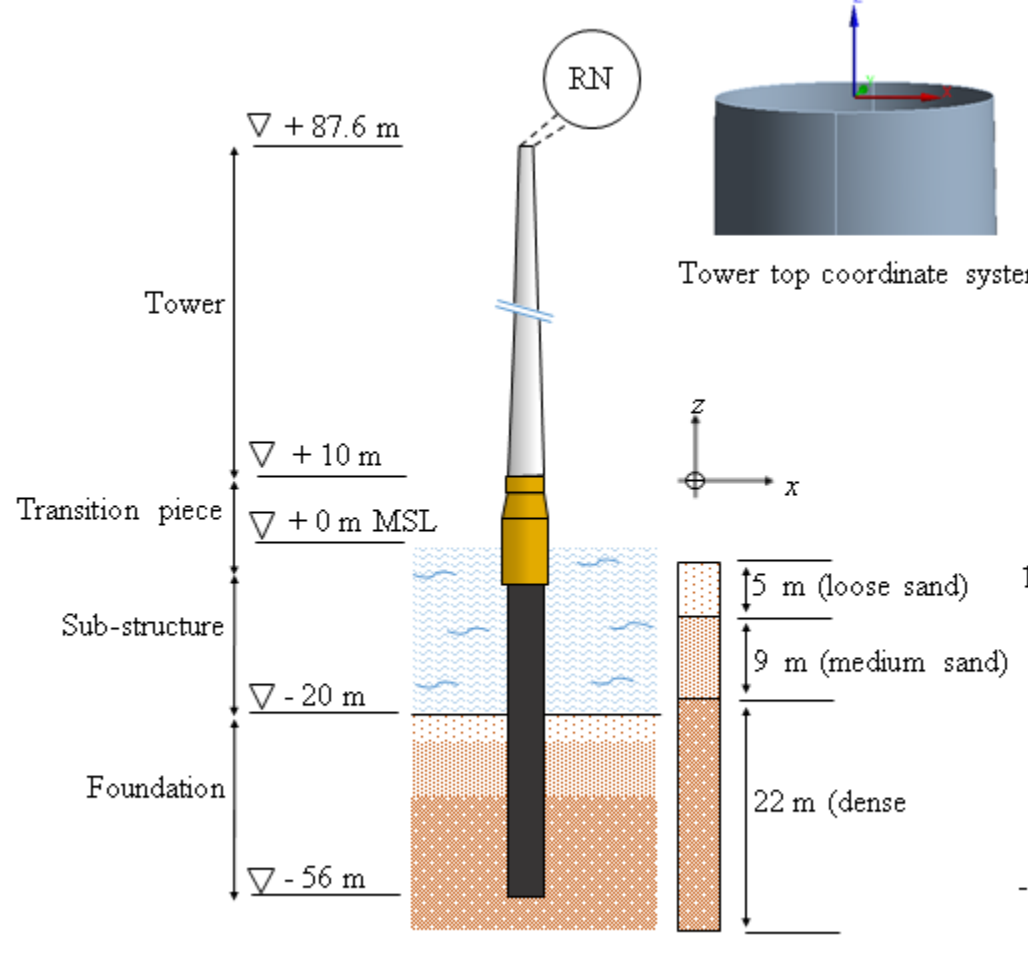

(a)

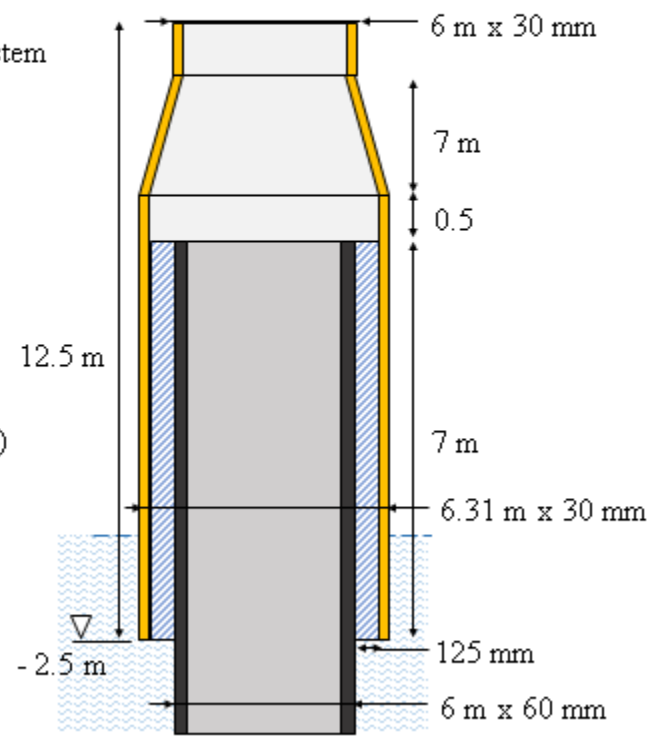

(b)

Figure 2. Geometry: a Representation of the adapted NREL 5MW and OC3 Monopile geometry embedded in layered sandy soil, $\mathbf{b}$ details of the transition piece adapted geometry

\section{Design Load analysis}

\subsection{Site-specific met-ocean characteristics}

The assumed site in this study is situated in the Dutch part of the North Sea, $8 \mathrm{~km}$ away from the shore of IJmuiden city and refers to the NL-1 location in Ref. [5]; it is proved to be a particularly appropriate site for monopile deployment. Furthermore, it closely matches the wind class, soil condition and water depth considered in this study. The NREL 5MW OWT was designed to operate with Class I wind, according to the classification of IEC 61400-1 standard [47]. Characteristics of the wind conditions are derived from this classification. Regarding the wave conditions, a PiersonMoskowitz wave spectrum [43], characterised by the significant wave height and peak spectral period, is used in this study. The main specific met-ocean data of this site are summarised in Table 2. 


\begin{tabular}{|c|c|c|c|}
\hline \multicolumn{2}{|l|}{ Wind conditions (Class I) } & \multicolumn{2}{|l|}{ Marine conditions } \\
\hline Reference wind speed $V_{r e f}[\mathrm{~m} / \mathrm{s}]$ & 50 & 50-year significant wave height $H_{s 50}[\mathrm{~m}]$ & 6.9 \\
\hline Annual average wind speed $V_{a v e}[\mathrm{~m} / \mathrm{s}]$ & 10 & 50-year peak spectral period $T_{s 50}[\mathrm{~s}]$ & 7.7 \\
\hline \multirow[t]{3}{*}{50 -year extreme $3 \mathrm{~s}$ gust wind speed $V_{g 50}[\mathrm{~m} / \mathrm{s}]$} & 60 & Average significant wave height $H_{a v e}[\mathrm{~m}]$ & 2 \\
\hline & & Average wave period $T_{a v e}[\mathrm{~s}]$ & 5 \\
\hline & & 50 -year extreme current speed $V_{c, 50}[\mathrm{~m} / \mathrm{s}]$ & 0.8 \\
\hline
\end{tabular}

\subsection{Sources of loads}

OWTs are subjected to multiple load sources imposed by their environment. A relevant list of loads that should be taken into account for the design of support structures are suggested in design standards, such as IEC 61400-3 [48] and DNVOS-J101 [49]. Formulations and calculations of each environmental load were derived in this study according to DNVRP-C205 [50]. As depicted in Fig. 3, the loads on the support structure can be roughly categorised into six groups, i.e. 1) loads; and 6) hydrostatic loads.

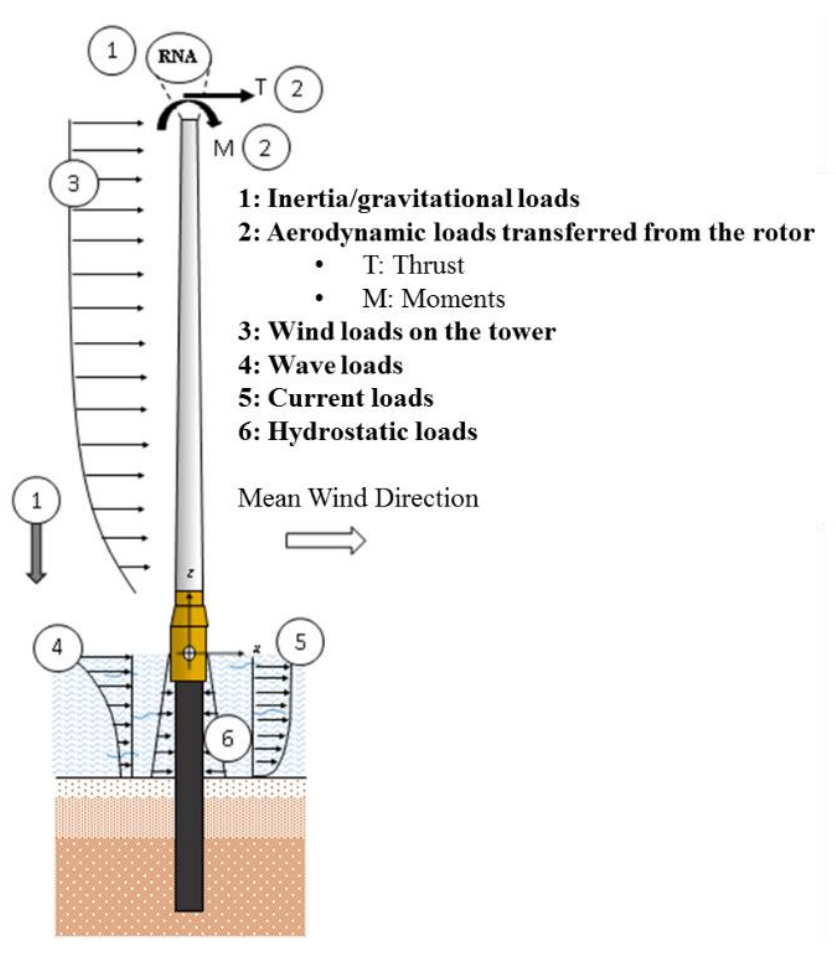

Figure 3. Loads on the support structure

The loads depicted in Fig. 3 are detailed below. 


\subsubsection{Inertia loads}

The inertia loads, due to the mass of the support structure and the RNA mass at the top of the tower (see Table 1), can significantly contribute to buckling and affect the modal frequencies of the OWT support structure, and therefore they should be taken into account in the structural analysis of support structures.

\subsubsection{Aerodynamic loads transferred from the rotor}

The aerodynamic loads applied on the rotor are transferred to the tower top and are commonly decomposed into a load matrix defined in the wind turbine referential axis. The typical values of loads for the design of the steel tower were extracted from [51] and were originally defined during the WindPACT (Wind Partnership for Advanced Component Technologies) Turbine Rotor Design Study [52]. The fatigue loads were obtained through the Damage Equivalent Load (DEL) method, developed by NREL and detailed in [53]. The DEL method was applied to the NedWind 25 fatigue-load spectrum and good results were achieved [53], which confirms the validity of the DEL method.

\subsubsection{Wind loads on the tower}

Wind loads acting on the tower structure result from drag and are dependent on the mean wind velocity $\bar{V}(z)$. A power law profile is generally used to represent the wind shear, defined by the following equation:

$$
\bar{V}(z)=\bar{V}_{r}\left(\frac{z}{z_{r}}\right)^{\alpha}
$$

where $\bar{V}_{r}$ represents the reference wind speed measured at the nacelle altitude $z_{r}$, and $\alpha$ is the roughness coefficient which is equal to 0.115 for offshore site [45]. Wind loads along the tower are then determined from:

$$
F_{\text {tower }}(z)=\frac{1}{2} \rho_{a} C_{D, T} D(z) \bar{V}_{r}^{2}(z)
$$

where $C_{D, T}$ is the drag coefficient of the tower, taken as 1.0 from [39], $D(z)$ is the external diameter of the tower at height $z$ as the tower is tapered.

\subsubsection{Wave loads}

According to DNV-OS-J101 [49], Morison's equation can be employed to estimate the wave loads on the structure when the diameter of the structure, $D$, is smaller than one fifth of the wave length $\lambda$, i.e.:

$$
D \leq 0.2 \lambda
$$

For shallow water waves, the wave length $\lambda$ is given by [54]:

$$
\lambda=T \sqrt{g h}
$$

where $T$ is the wave period, $g$ is the gravity acceleration with a typical value of $9.81 \mathrm{~m} / \mathrm{s}^{2}, h$ is the water depth. 
In this case, wave period and water depth are $5 \mathrm{~s}$ and $20 \mathrm{~m}$, respectively. Thus, the wave length $\lambda$ is $70 \mathrm{~m}$, which is 11.6 times larger than the diameter of the monopile used in this study, satisfying the condition defined in Eq. (3). Thus, Morison's equation is deemed to be an appropriate method to calculate wave loads in this study.

According to Morison's equation, the wave loads are composed of an inertia and a drag term:

$$
\mathrm{F}_{\text {wave }}(\mathrm{z})=\frac{1}{4} \rho_{\mathrm{w}} \cdot \pi \cdot \mathrm{D}^{2} \cdot \mathrm{C}_{\mathrm{M}} \cdot \dot{\mathrm{u}}(\mathrm{z}, \mathrm{t})+\frac{1}{2} \rho_{\text {water }} \cdot \mathrm{D} \cdot \mathrm{C}_{\mathrm{D}} \cdot \mathrm{u}(\mathrm{z}, \mathrm{t}) \cdot|\mathrm{u}(\mathrm{z}, \mathrm{t})|
$$

where $\rho_{w}$ is the water density, with typical value of $1025 \mathrm{~kg} / \mathrm{m}^{3} ; C_{M}$ and $C_{D}$ are the inertia and drag coefficient of the monopile, taken respectively as 1.6 and 1.0 from [25]; $\mathrm{u}(\mathrm{z}, \mathrm{t})$ and $\dot{\mathrm{u}}(\mathrm{z}, \mathrm{t})$ are respectively horizontal velocity and acceleration of water particles, which can be obtained from linear/Airy wave theory [55].

\subsubsection{Current loads}

Current can induce drag loads on the support structure. An exponential profile for sub-surface current is used to describe the current velocity $u_{c}(z)$ from MSL to seabed $d$ :

$$
u_{c}(z)=u_{c, M S L}\left(\frac{d+z}{d}\right)^{1 / 7}
$$

where $u_{c, M S L}$ is the velocity of current at MSL, $d$ is the water depth from MSL to seabed. Assuming that the current and wave are aligned, current velocity is added to the wave particle velocity in the drag term of the Morison's equation in Eq. (5).

\subsubsection{Hydrostatic}

Immersion of the monopile into water induces hydrostatic pressure applied on its surface. This represents a permanent normal load, linearly increasing with the water depth. The hydrostatic force $F_{h}$ can be calculated by:

$$
F_{h}=\rho_{w} g h
$$

where $g$ is the gravitational constant, $h$ is the water depth.

\subsection{Design load cases}

Design standard IEC61400-3 [48] defines thirty-two load cases for the structural design of OWTs, covering all the operation conditions of an OWT, such as start up, normal operation, shut down and 50-year extreme conditions. The types of analyses of the thirty-two load cases can be categorised into two groups, i.e. ultimate and fatigue. For simplicity, the typical load cases used in the structural design of offshore wind turbines are generally the ultimate load under 50year extreme condition and fatigue load under normal sea condition. In this study, both ultimate and fatigue load cases are considered, and the details are presented below. 


\subsubsection{Ultimate load case}

The ultimate load case corresponds to the extreme environmental conditions that may be experienced by the OWT and is based on a 50-year return period. It was demonstrated that the NREL 5MW is governed by the wind loading, rather than wave loading [56]. Thus, the most critical ULS load case is often considered to correspond to the parked wind turbine, under the 50-years Extreme Wind Model (EWM) with the 50-years Reduced Wave Height (RWH) and Extreme Current Model (ECM), defined as the Design Load Case (DLC) 6.1b and 2.1 for IEC [48] and GL [57] standards, respectively. Load safety factors of 1.1 and 1.35 are applied on the gravitational load and other loads (i.e. wind, wave and current loads) [47], respectively.

\subsubsection{Fatigue load case}

The nature of wave loading as well as rotor operation during the OWT's lifetime induces a significant source of periodic loadings. Wind turbine support structures are therefore prone to fatigue failure [26]. A very commonly used fatigue load case corresponds to an operating state under Normal Turbulence Model (NTM) and Normal Sea State (NSS) where wave height and cross zero periods are obtained from the joint probability function of the site, assuming no current; it corresponds to the DLC 1.2 from the IEC standard [48] and is assumed to represent the entire fatigue state [58]. Load safety factor for fatigue is equal to 1.0, according to the IEC standard [47].

\subsubsection{Summary of design load cases}

Tables 3 and 4 summarise the factored aerodynamic loads and load cases considered in this study.

Table 3. Factored wind turbine aerodynamic loads [51]

\begin{tabular}{llll}
\hline Load case & Thrust force $[\mathrm{kN}]$ & Tilting moment $[\mathrm{kN}-\mathrm{m}]$ & Torsional moment $[\mathrm{kN}-\mathrm{m}]$ \\
\hline Ultimate load case & 781 & 38,567 & 7,876 \\
Fatigue load case & 197 & 3,687 & 3,483 \\
\hline
\end{tabular}

Table 4. Design Load cases

\begin{tabular}{llll}
\hline Load case & Wind conditions & Wave conditions & Load safety factor \\
\cline { 1 - 2 } Fatigue load case & NTM: & NSS: & $*$ \\
\cline { 1 - 2 } DLC 1.2 & $V_{\text {ave }}$ & $H_{\text {ave }}, T_{\text {ave }}$ & 1.0 \\
(Operating) & & No current & \\
\hline Ultimate load case & EWM: & RWH: & Normal N \\
\cline { 1 - 1 } DLC 6.1b/2.1 & $V_{g 50}$ & $1.32 \times H_{s 50}, T_{s 50}$ & $1.1 / 1.35$ \\
(Parked) & & ECM: $V_{c, e x}$ & \\
\hline
\end{tabular}




\section{Parametric FEA model}

\subsection{Model description}

A parametric FEA model of the support structure and the soil is established using ANSYS, which is a widely used multipurpose FEA commercial package. A flowchart of the model is presented in Fig. 4 and details of each step are illustrated by an application to the reference model defined in Section 2.

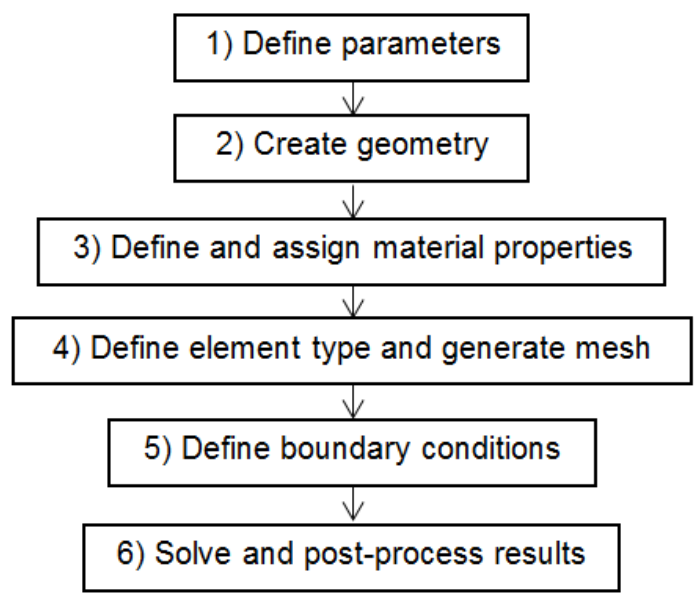

Figure 4. Flowchart of the parametric FEA model

\subsection{Application of the parametric model to the reference model}

\subsubsection{Define parameters}

In the first step, the parameters involved in the FEA modelling, such as structure thickness and geometry data, are defined.

\subsubsection{Create Geometry}

Based on the geometric dimensions presented in Section 2, the 3D geometry of the reference model is generated, consisting of five parts, i.e. tower, transition piece, grout, monopile and soil. Tower and monopile parts are discretised into 15 and 10 segments respectively, in order to represent the varying thicknesses. The diameter of the soil is 20 times the diameter of the monopile, which is large enough to ensure no artificial boundary effects on pile-soil behaviour. The created 3D geometry model is depicted in Fig. 5. 


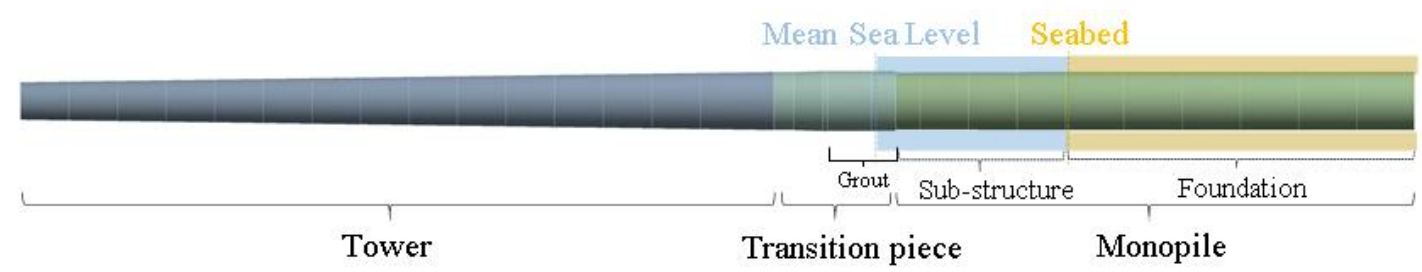

(a)

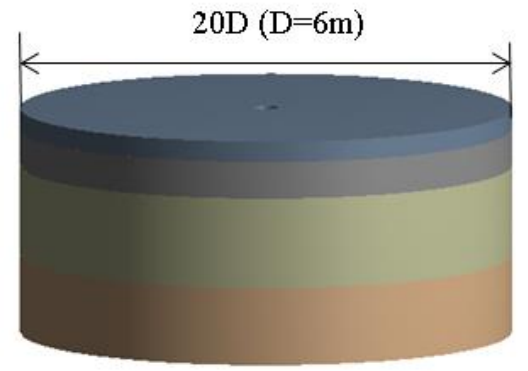

(b)

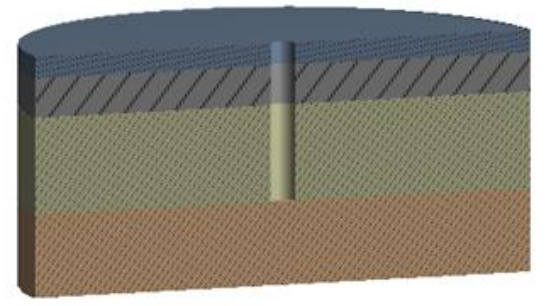

(c)

Figure 5. 3D geometry model: a support structures, $\mathbf{b}$ soil model, $\mathbf{c}$ section view of soil model

\subsubsection{Define and assign material properties}

The main part of the support structure is made of steel S355, which has been widely used for OWT support structures [25]. According to [44], density of the steel S355 is artificially increased by $8 \%$ to account for secondary steel appurtenances, welds and coatings that are not accounted for in the thicknesses data of the support structure.

Regarding the grout, commercial data from a high strength concrete Ducorit D $4{ }^{\circledR}$ [59], which is commonly used in OWT grouted connections [46], is chosen in this study. The Tresca failure criterion used for brittle material is applied to the grout. Mechanical properties of the support structure materials are summarised in Table 5.

Table 5. Material properties of the support structure

\begin{tabular}{lll}
\hline Properties & Steel [25] & Grout [59] \\
\hline Young's modulus [GPa] & 210 & 70 \\
Poisson's ratio [-] & 0.38 & 0.19 \\
Density [kg/m ${ }^{3}$ ] & 8500 & 2740 \\
Compressive strength [MPa] & - & 200 \\
Tensile strength [MPa] & - & 10 \\
Yield Strength [MPa] & 355 & - \\
\hline
\end{tabular}

The constitutive model of sand is well described by the Drucker-Prager model [60], which is pressure dependent and has been widely used for soil modelling. According to the Drucker-Prager model, the yield strength of the soil, $\sigma_{y, s}$, can be expressed in terms of the internal friction angle $\phi$ and the cohesion value $c$ using the following equation: 


$$
\sigma_{y, s}=\frac{6 c \cos (\phi)}{\sqrt{3}(3-\sin (\phi))}
$$

The frictional coefficient $C_{f}$ between the pile and the soil is given by [23]:

$$
C_{f}=\tan \left(\frac{2}{3} \phi\right)
$$

Properties of soil materials used in this study are adapted from [23] and [61] in order to match the soil characteristics of the site, and are listed in Table 6.

Table 6. Sand properties for the different soil layers [23, 61]

\begin{tabular}{lllllll}
\hline $\begin{array}{l}\text { Type of } \\
\text { sand }\end{array}$ & $\begin{array}{l}\text { Unit weight } \\
{[\mathrm{kN} . \mathrm{m}-3]}\end{array}$ & $\begin{array}{l}\text { Young's } \\
\text { modulus [MPa] }\end{array}$ & $\begin{array}{l}\text { Angle of } \\
\text { Friction [deg.] }\end{array}$ & $\begin{array}{l}\text { Cohesion } \\
{[\mathrm{kPa}]}\end{array}$ & $\begin{array}{l}\text { Yield stress } \\
{[\mathrm{kPa}]}\end{array}$ & $\begin{array}{l}\text { Friction coeff } \\
{[-]}\end{array}$ \\
\hline Loose & 10 & 30 & 33 & 50 & 59.2 & 0.40 \\
Medium & 10 & 50 & 35 & 50 & 58.5 & 0.43 \\
Dense & 10 & 80 & 38.5 & 50 & 57.0 & 0.48 \\
\hline
\end{tabular}

\subsubsection{Define element type and generate mesh}

Because the tower, transition piece and monopile are thin-wall structures, they can be effectively and accurately modelled using shell elements. The element type used here is shell element Shell281, which has eight nodes with six degrees of freedom. It is well suited for linear, large rotation and/or large strain nonlinear application. The Shell281 element is defined in ANSYS and its details can be found in ANSYS help documentation [62]. Following standard guidelines [25] and experimental results [46], grout was modelled using $2^{\text {nd }}$ order solid elements (SOLID186) in order to allow bending stress to develop and propagate. Finally, the different soil layers are modelled with linear order solid elements (SOLID185). Mesh convergence exercises are performed to determine the proper mesh size. Five parameters are defined in order to well control the mesh, i.e. 1) number of divisions on circumferential edges of the support structure $\left.N_{C E, S T} ; 2\right)$ element size of longitudinal edges of the support structure $\left.E S_{L E, S T} ; 3\right)$ number of divisions on circumeferential edges of the soil $N_{C E, \text { Soil }}$;) element size of longitudinal edges of the soil $E S_{L E, S o i l}$; and 5) number of divisions on radial edges of the soil $N_{R E, \text { Soil }}$. Additionally, a bias factor of 15 is applied to the mesh on radial edges of soil, ensuring a finer mesh near the contact regions of monopile and soil. Four sets of meshing parameters (see Table 7) are investigated. In this case, a point load of $100 \mathrm{kN}$ is applied on the tower top. The calculated maximum von-Mises stress is presented in Table 7. As can be seen from Table 7, the maximum von-Mises stress converges at Refinment 2, with a relative difference $(0.44 \%)$ when comparing to the further mesh refinement. Therefore, meshing parameters for Refinement 2 are deemed appropriate and thus chosen in this study. The created mesh is depicted in Fig. 6. 
Table 7. Meshing parameters and calculated maximum von-Mises stress

\begin{tabular}{|c|c|c|c|c|c|c|c|c|}
\hline ID & $\begin{array}{l}N_{C E, S T} \\
{[-]}\end{array}$ & $\begin{array}{l}E S_{L E, S T} \\
{[\mathrm{~m}]}\end{array}$ & $\begin{array}{l}N_{C E, \text { Soil }} \\
{[-]}\end{array}$ & $\begin{array}{l}E S_{L E, \text { Soil }} \\
{[\mathrm{m}]}\end{array}$ & $\begin{array}{l}N_{R E, \text { Soil }} \\
{[-]}\end{array}$ & $\begin{array}{l}\text { Number of } \\
\text { elements }\end{array}$ & $\begin{array}{l}\text { Maximum von- } \\
\text { Mises stress } \\
{[\mathrm{MPa}]}\end{array}$ & $\begin{array}{l}\text { Diff } \\
{[\%]}\end{array}$ \\
\hline Meshing 1 & 16 & 4 & 16 & 8 & 4 & 1,648 & 23.2 & 1.75 \\
\hline Refinement 1 & 32 & 2 & 32 & 4 & 8 & 6,460 & 22.8 & 0.88 \\
\hline Refinement 2 & 64 & 1 & 64 & 2 & 12 & 35,264 & 22.6 & 0.44 \\
\hline Refinement 3 & 128 & 0.5 & 128 & 1 & 24 & 217,108 & 22.5 & - \\
\hline
\end{tabular}

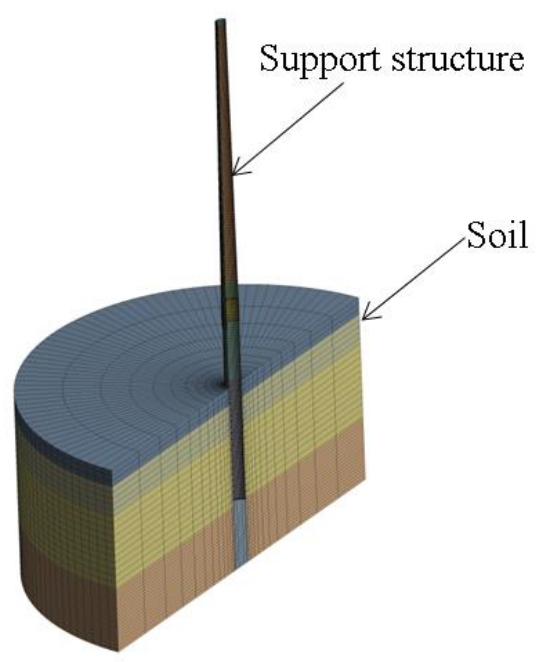

(a)

\subsubsection{Define boundary conditions}

Loads applied on the OWT support structure for both ultimate and fatigue load cases are the ones defined in Section 3. Wind turbine rotor aerodynamic loads are applied on top of the tower. Other loads (i.e. wave, current and wind loads as well as hydrostatic loads) are applied using pressure formulations, which enable these loads update automatically with the updated diameters of the support structure during the optimisation process, ensuring a more realistic representation. Thus, wave, current and wind pressure are applied on the upwind-side outer surface of the support structure while hydrostatic loads are surrounding the submerged components. The RNA is represented as a lumped mass, applied via multi-point constraint on the tower top.

The bottom of the soil model is fixed against translation in all directions, whereas the lateral boundaries of the soil model are fixed against lateral translation. A frictional contact based on an augmented Lagrangian formulation [62] is defined 
between the pile and the soil with the appropriate friction coefficients (see Table 6), enabling soil-solid interaction. Any other contacts (such as tower to transition piece contact) are simplified with a bonded formulation. The frictional contact formulation and nonlinearity from the soil behaviour involve multiple step analysis to make the solution converge.

\subsubsection{Solve and post-process results}

Having defined design parameters, geometry, materials, element types, mesh and boundary conditions, a variety of analyses (such as buckling, fatigue and modal analyses) can be performed. The simulation results, such as deformations and stress distributions of both support structure and soil, are then plotted using the post-processing functions of ANSYS software.

\subsection{Validation of the parametric FEA model}

Two case studies, based on the NREL 5MW OWT on OC3 monopile, are performed to validate the parametric FEA model.

\subsubsection{Modal analysis}

Considering the analysis of the natural frequencies, the present FEA model has been compared to reference values in two different configurations, i.e. fixed soil [45] and flexible soil [23].

As can been seen from Table 8, the first two frequencies of fore-aft and side-to-side modes obtained from the present FEA model show good agreement with the reference values for both configurations, with the maximum percentage difference $(4.6 \%)$ observed for the $2^{\text {nd }}$ fore-aft mode with flexible soil. This confirms the validity of the present FEA model.

From Table 8 it can also be observed that the types of soil modelling (i.e. fixed or flexible) can significantly affect the natural frequencies of support structures.

Table 8. Comparison of the support structure mode frequencies with reference values

\begin{tabular}{|c|c|c|c|c|c|c|}
\hline \multirow{2}{*}{$\begin{array}{l}\text { Mode frequencies } \\
(\mathrm{Hz})\end{array}$} & \multicolumn{3}{|c|}{ Fixed Soil } & \multicolumn{3}{|c|}{ Flexible Soil } \\
\hline & Present & Ref. [45] & $\%$ Diff & Present & Ref. [23] & $\%$ Diff \\
\hline 1 st Fore-Aft & 0.276 & 0.277 & $-0.5 \%$ & 0.245 & 0.242 & $1.6 \%$ \\
\hline 1st Side-to-side & 0.278 & 0.278 & $-0.1 \%$ & 0.248 & 0.241 & $3.2 \%$ \\
\hline 2nd Fore-Aft & 1.573 & 1.600 & $-1.7 \%$ & 1.304 & 1.366 & $-4.6 \%$ \\
\hline 2nd Side-to-side & 1.838 & 1.807 & $1.7 \%$ & 1.423 & 1.489 & $-4.4 \%$ \\
\hline
\end{tabular}




\subsubsection{Deflections in static analysis}

This case study aims to assess the deflection behaviour of the support structure in a static analysis. In the reference case study [63], the weight of the RNA and a $2 \mathrm{MN}$ rotor thrust load were applied on top of the structure. The present model is adapted to comply with the shift of RNA centre of mass used in the reference model. The deflections at the RNA level and tower base are compared, and results are presented in Table 9. The displacements at RNA and tower base under loaded condition are measured with respect to the RNA location and tower base centre under unloaded condition, respectively.

Table 9. Static Deformation of the NREL 5 MW on OC3 monopile

\begin{tabular}{llllllll}
\hline \multirow{2}{*}{$\begin{array}{l}\text { Load case } \\
\text { Mass/Thrust }\end{array}$} & \multicolumn{2}{l}{ Displacement at RNA } & & \multicolumn{3}{c}{ Displacement at Tower base } \\
\cline { 2 - 4 } \cline { 6 - 8 } \cline { 6 - 8 } & Present & Ref. [63] & \% Diff & & Present & Ref. [63] & \% Diff \\
\hline RNA / 2MN & $1.649 \mathrm{~m}$ & $1.644 \mathrm{~m}$ & $-0.3 \%$ & & $0.084 \mathrm{~m}$ & $0.088 \mathrm{~m}$ & $-4.5 \%$
\end{tabular}

As can be seen from Table 9, good agreement is achieved when comparing the results of the present FEA model against the values reported in [63], for both displacements at the RNA and tower base, with a maximum relative difference $(-4.5 \%)$ observed for displacement at the tower base. This further confirms the validation of the present FEA model.

\section{Genetic algorithm}

A GA [33] is chosen in this study for finding the optimum solutions. The GA is a search procedure based on genetics and natural selection mechanisms. It tends to imitate how evolutionary processes have remarkably succeeded in optimising nature. A GA is based on two concepts to translate the optimisation problem into an evolution process, i.e. a fitness function and a genetic representation.

The performance of an individual is assessed through a fitness function. This function should be a measure of how well the design point performs, relative to the chosen objective function, and how well it adapts to its environment, which is defined by the satisfaction of design and structural constraints. In a GA, a design point is defined as a chromosome, containing all the variables of the system, which are defined as genes. Earlier GA used binary encoding to define the genetic string of the chromosome, but now, real-number and integer coding are also possible [64]. Having defined the fitness function and genetic representation, GA proceeds to initialise a population of candidate solutions and then to improve the population through repeatedly using crossover and mutation operators.

\section{Structural optimisation of offshore wind turbine support structure}

\subsection{Objective function}


The mass reduction in an OWT support structure is beneficial to reduce the material costs of the support structure, achieving successful and economic operation. As this study focuses on an integrated optimisation approach, the minimum global mass of the support structure $M_{\text {global }}$ is chosen as objective function $F_{o b j}$. This is expressed as:

$$
F_{o b j}=\min \left(M_{\text {global }}\right)
$$

\subsection{Design variables}

The main variables considered for optimisation of a monopile support structure are the thickness and diameters of the different sections. Indeed, these two types of variable have a great influence on the structural response and are individually design-driven by different criteria [13].

By defining several segments along the support structure, the number of variables for thickness increases greatly which can impose difficulties to numerically solving the problem. In this case, the tower and monopile consist of 15 and 10 segments, respectively. Taking the thickness of each segment as variable requires 25 variables, and other 5 variables are needed for transition piece thickness, tower top diamter, tower bottom diamter, monopile top diameter and monopile bottom diamter, resulting in 30 variables in total. A reduction technique used effectively by [43] is to define thickness at their top and bottom ends, and the intermediate variable values are then derived by a linear interpolation. This strategy has been adopted in this study for the foundation, sub-structure and tower, decreasing the total number of variables from 30 to 13. Given the length of the tower, three linear interpolations are introduced instead of one, in order to provide more degrees of freedom. Due to installation limitations, the diameter of the foundation is assumed to stay constant all along its length.

Therefore, inspired by the chromosome formulation, a set of design variables for a design point $j$ can be expressed as a vector of variables:

$$
X_{j}=\left[x_{1} x_{2} \cdots x_{n}\right]^{T}, n=13
$$

where $x_{1}$ and $x_{2}$ are the diameters at the base and top of the monopile, respectively; $x_{3}$ and $x_{4}$ are the diameters at the base and top of the tower, respectively; $x_{5} \sim x_{8}$ are used to define different thicknesses along the tower: $x_{5}$ at the base of the tower, $x_{6}$ and $x_{7}$ at two intermediate locations and $x_{8}$ at the top of the tower; $x_{9}$ and $x_{10}$ are the thicknesses at the base and top of the sub-structure, respectively; $x_{11}$ and $x_{12}$ are the thicknesses at the base and top of the foundation, respectively. Finally, $x_{13}$ is the thickness of the transition piece. The different locations of the variables along the support structure are illustrated in Fig. 7. 


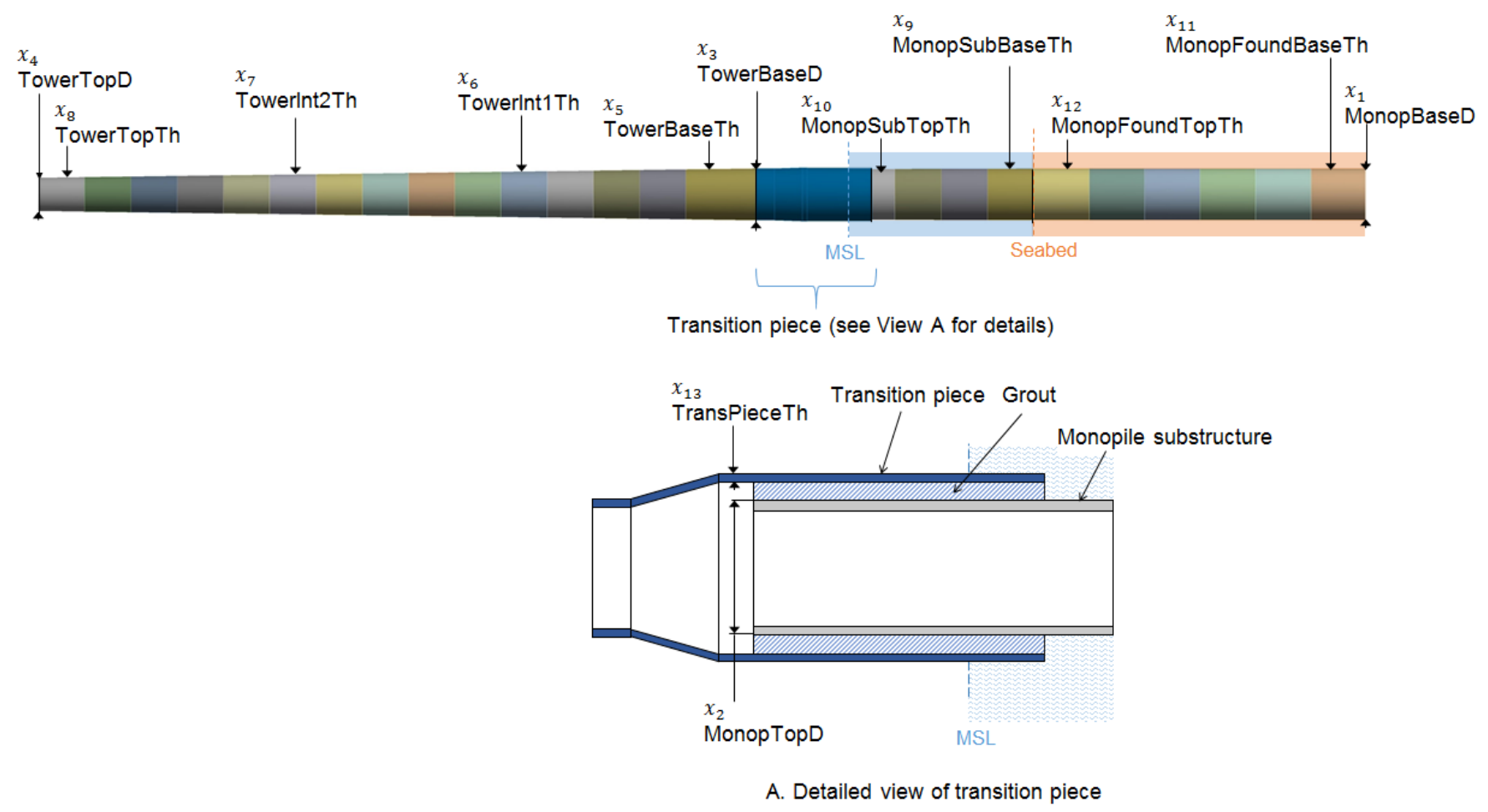

Figure 7. Schematic of the design variables of the support structure

\subsection{Constraints and design criteria}

Choice of criteria is of paramount importance for the reliability of the solution provided by the optimisation. Wrong choice, or lack of relevant criteria, could lead to unrealistic results, and unexpected structural failure during experimental tests or structure lifetime [65]. According to DNV-OS-J101 [49], three limit states should be considered in the design of OWT support structures, i.e. 1) ultimate limit state (ULS), which corresponds to the maximum loading-carrying resistance (i.e. yielding stress and buckling); 2) fatigue limit state (FLS), which corresponds to failure due to fatigue loads; and 3) serviceability limit state (SLS), which correspond to tolerance criteria (i.e. deflections and vibrations) applicable to normal use. Therefore, in this study, the structural optimisation of OWT support structures takes account of six constraint conditions, i.e. vibration (SLS), stress (ULS), deformation (SLS), buckling (ULS), fatigue (FSL) and design variable constraints, covering the three limit states suggested in DNV standard. 


\subsubsection{Vibration constraint}

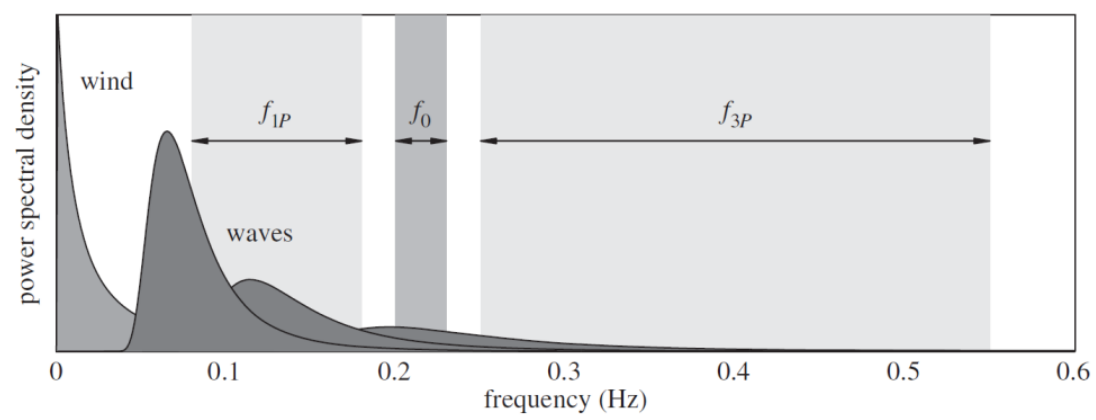

Figure 8. Illustration of typical excitation ranges of a modern offshore wind turbine [13]

$$
f_{1 P+5 \%} \leq f_{1 s t} \leq f_{3 P-5 \%}
$$

The cut-in and rated rotor speed of the NREL 5MW are equal to $6.9 \mathrm{rpm}$ and $12.1 \mathrm{rpm}$, respectively. Thus, resonance constraints could be expressed by:

$$
0.212 \leq f_{1 s t} \leq 0.328 \mathrm{~Hz}
$$

\subsubsection{Stress constraint}

In terms of ULS (ultimate limit state), the maximum stress in the grouted connection $\sigma_{T, \max }$ (Tresca) and in the rest of the support structure $\sigma_{V M \text {, max }}$ (von Mises) should stand below the allowable stresses limits $\sigma_{T, \text { allow }}$ and $\sigma_{V M \text {,allow }}$, respectively. This is described by the following inequality:

$$
\begin{aligned}
& \sigma_{V M, \max } \leq \sigma_{V M, \text { allow }} \\
& \sigma_{T, \max } \leq \sigma_{T, \text { allow }}
\end{aligned}
$$

The allowable stress values $\sigma_{T, \text { allow }}$ and $\sigma_{V M, \text { allow }}$ are given by:

$$
\sigma_{V M, \text { allow }} \leq \frac{\sigma_{y, \text { steel }}}{\gamma_{m} \cdot \gamma_{f}}
$$




$$
\sigma_{T, \text { allow }} \leq \frac{\sigma_{c, \text { ulti }}}{\gamma_{m}}
$$

where $\sigma_{y, \text { steel }}$ is the yield strength of the steel component; $\sigma_{c, u l t i}$ is the ultimate compressive strength of the grout; and $\gamma_{m}$ and $\gamma_{f}$ are the partial safety factors for material and consequence of failure, respectively. According to DNV-OS-J101 [49], capacity of structural elements in yielding should be checked in ultimate limit states. Therefore, the yield strength is used in Eq. (16) for steel components in this study.

From Table 5, it appears that yield strength for S355 steel is $355 \mathrm{MPa}$. The partial safety factors for material $\gamma_{m}$ and failure $\gamma_{f}$ are 1.1 and 1.0 [47], respectively. Thus, the allowable stress $\sigma_{V M, \text { allow }}$ is $323 \mathrm{MPa}$. The ultimate compressive strength of the grout is $200 \mathrm{MPa}$ (Table 5) and a partial safety factor for material $\gamma_{m}$ of 3 should be applied for ULS [25]. Thus, $\sigma_{T, \text { allow }}$ is equal to $67 \mathrm{MPa}$.

\subsubsection{Deformation constraint}

In order to avoid the uncertainties introduced by large deformations and to ensure the overall structural stability, deflection and rotation constraints are defined, ensuring both the pile-head deflection $d_{\text {pile }}$ and the rotation $\theta_{\text {seabed }}$ at the mudline stay below the allowable values $d_{\text {allow }}$ and $\theta_{\text {allow }}$, respectively. This can be expressed by:

$$
\begin{aligned}
& d_{\text {pile }} \leq d_{\text {allow }} \\
& \theta_{\text {seabed }} \leq \theta_{\text {allow }}-\theta_{\text {inc }}
\end{aligned}
$$

where, $\theta_{\text {inc }}$ is the rotation due to installation incertitude and is chosen empirically here at $0.1^{\circ}$. The values of $d_{\text {allow }}$ and $\theta_{\text {allow }}$ are fixed at $0.1 \mathrm{~m}$ and $0.5^{\circ}$ respectively, according to DNV standard [25].

\subsubsection{Buckling constraint}

In addition to the large RNA mass at the tower top, the slenderness of a monopile support structure forces investigation of the risk of instability due to buckling. The results of the ULS static analysis are used as pre-stress loads. To avoid failures, the load multiplier $L_{m}$, which is the ratio of the critical load to the current applied load, should be larger than the allowable load multiplier $L_{m, \text { allow }}$. This constraint can be expressed by:

$$
L_{m} \geq L_{m, \text { allow }}
$$

In this study, 1.4 is chosen as the value for $L_{m, \text { allow }}$, according to DNV standard [25].

\subsubsection{Fatigue constraint}


Fatigue is particularly important in structures (such as OWT support structures) subject to significant cyclic loads. During the operation of the wind turbine, every rotor rotation causes stress changes in the support structure. Additionally, the availability of the turbine reflects if the rotor is operating. The design life number of cycles $N_{\text {life }}$ can be then estimated based on rated rotor speed $n_{\text {rated }}$ and availability $\eta_{a}(98.5 \%)$ on the selected location [5]. Thus, considering a lifetime requirement of 20 years [48], the number of cycles is equal to:

$$
N_{\text {life }}=\eta_{a} \cdot n_{\text {rated }} \times(20[\text { year }] \times 365[\text { day } / \text { y ear }] \times 24[\text { hour/day }] \times 60[\text { min } / \text { hour }])
$$

Based on the efficiency of the DEL method used in this study, computational cost is reduced to an equivalent load case where the number of cycles to failure $N_{D E L}$ can be derived from an equivalent S-N curve. An appropriate S-N curve of slope $m=4$ and $\log \bar{a}=13.93$ was provided by [51] with the DEL loads defined in Section 3. The design life number of cycles $N_{\text {life }}$ calculated from Eq. (21) can be used in the S-N curve to derive the design fatigue stress range $\sigma_{f, d e s i g n}$. The maximum fatigue stress range $\sigma_{f, \max }$ in the structure subjected to the fatigue loads is obtained from the FEA simulations. The minimum fatigue safety ratio $f_{s r \text {,min }}$ can then be derived from the ratio of the design fatigue stress range $\sigma_{f, d e s i g n}$ over the maximum fatigue stress range $\sigma_{f, \text { max }}$ in the structure. This safety ratio should stay above the allowable fatigue safety ratio $f_{\text {sr,allow }}$ which is equal to one times the material PSF $\gamma_{m, f}$ for fatigue:

$$
f_{s r, \min } \geq f_{s r, \text { allow }}
$$

Since the PSF of material for FLS is 1.15 [25], $f_{\text {sr,allow }}$ is equal to 1.15.

\subsubsection{Design variable constraint}

To ensure a feasible and realistic design, each design variable is constrained to vary within a range defined by upper and lower bound:

$$
x_{i}^{L} \leq x_{i} \leq x_{i}^{U} \quad i=1,2 \ldots 13
$$

where $x_{i}^{L}$ and $x_{i}^{U}$ are the lower and upper bounds of the design variables respectively.

The resultant loads on both the tower and monopile substructure generally increase from top to bottom, requiring larger diameter on the bottom of the tower and monopile substructure. Thus, the following constraint is defined:

$$
x_{i}-x_{i+1} \geq 0 \quad i=1,2,3
$$

Additionally, the thicknesses of tower and monopile substructure generally decrease from the bottom to the top. This is ensured by the following constraint:

$$
\begin{aligned}
& x_{i}-x_{i+1} \geq 0 \quad i=5,6,7 \\
& x_{i}-x_{i+1} \geq 0 \quad i=9
\end{aligned}
$$

The bounds of the design variables and constraints are presented in Tables 10 and 11, respectively. 
Table 10. Upper and lower bounds of the design variables

\begin{tabular}{llll}
\hline Design variable & $\begin{array}{l}\text { Lower } \\
\text { bound }\end{array}$ & Upper bound & Variable definition \\
\hline$x_{1}$ MonopBaseD $[\mathrm{m}]$ & 5 & 7 & Diameter of monopile base \\
\hline$x_{2}$ MonopTopD [m] & 5 & 7 & Diameter of monopile top \\
\hline$x_{3}$ TowerBaseD [m] & 5 & 7 & Diameter of tower base \\
\hline$x_{4}$ TowerTopD [m] & 3 & 4.5 & Diameter of tower top \\
\hline$x_{5}$ TowerBaseTh $[\mathrm{m}]$ & 0.020 & 0.040 & Thickness of tower base \\
\hline$x_{6}$ TowerInt1Th [m] & 0.020 & 0.040 & Thickness of tower Intermediate location 1 \\
\hline$x_{7}$ TowerInt2Th [m] & 0.015 & 0.035 & Thickness of tower Intermediate location 2 \\
\hline$x_{8}$ TowerTopTh [m] & 0.010 & 0.030 & Thickness of tower top \\
\hline$x_{9}$ MonopSubBaseTh [m] & 0.045 & 0.070 & Thickness of monopile substructure base \\
\hline$x_{10}$ MonopSubTopTh [m] & 0.045 & 0.070 & Thickness of monopile substructure top \\
\hline$x_{11}$ MonopFoundBaseTh [m] & 0.040 & 0.070 & Thickness of monopile foundation base \\
\hline$x_{12}$ MonopFoundTopTh [m] & 0.045 & 0.070 & Thickness of monopile foundation top \\
\hline$x_{13}$ TransPieceTh [m] & 0.025 & 0.040 & Thickness of transition piece \\
\hline
\end{tabular}

Table 11. Upper and lower bounds of the constraint conditions

\begin{tabular}{lll}
\hline Constraints & Lower bound & Upper bound \\
\hline $1^{\text {st }}$ Natural frequency $f_{1 s t}[\mathrm{~Hz}]$ & 0.212 & 0.328 \\
\hline Max Von Mises Stress $\sigma_{V M, \text { max }}[\mathrm{MPa}]$ & - & 323 \\
\hline Max Tresca stress $\sigma_{T, \text { max }}[\mathrm{MPa}]$ & - & 67 \\
\hline Pile head deflection $d_{p i l e}[\mathrm{~m}]$ & - & 0.1 \\
\hline Pile head Rotation $\theta_{\text {seabed }}\left[{ }^{\circ}\right]$ & - & 0.4 \\
\hline Buckling Load mult. $L_{m}[-]$ & 1.4 & - \\
\hline Fatigue safety ratio $f_{s r, \text { min }}[-]$ & 1.15 & - \\
\hline
\end{tabular}

\subsection{Parameter settings of the genetic algorithm}

The GA algorithm presented in Section 5 is chosen to search for optimal solutions. Table 12 presents the main parameters of GA. 
Table 12. Main parameters of GA

\begin{tabular}{|c|c|}
\hline Item & Value \\
\hline Type of initial sampling & Constrained sampling \\
\hline Number of initial samples $N_{I n i}$ & 200 \\
\hline Number of samples per iteration $N_{\text {Perrni }}$ & 55 \\
\hline Convergence stability criteria & $1.5 \%$ \\
\hline Maximum number of iterations $N_{\text {Maxtler }}$ & 25 \\
\hline Crossover probability & 0.01 \\
\hline Mutation probability & 0.9 \\
\hline
\end{tabular}

Each parameter in Table 12 is detailed below.

\subsubsection{Type of initial sampling}

Since design constraints have been formulated above, a constrained sampling algorithm is used, based on the satisfaction of Eqs. (23) and (24).

\subsubsection{Number of initial samples}

Minimum value of 10 times the number of design variables should be chosen for number of initial samples $N_{I n i}$. In this study this value is increased to 200 points in order to increase the chance of finding a better solution.

\subsubsection{Number of samples per iteration}

The number of samples per iteration $N_{\text {Perter }}$ has an influence on convergence speed. An empirical value of 55 is chosen in this study.

\subsubsection{Convergence stability percentage}

The convergence criterion is derived based on maximum spread, mean and standard variation of the output parameters. In this study, optimisation is assumed converged, i.e. population is homogeneous when the criterion value reached $1.5 \%$.

\subsubsection{Maximum number of iterations}

The maximum number of iterations $N_{\text {Maxter }}$ (25 in this study) is the stopping criterion of the GA. It provides an estimation of the maximum number of evaluations $N_{\text {Maxval }}$, which is defined from previous parameters: 


$$
N_{\text {MaxEval }}=N_{\text {Ini }}+N_{\text {Perlter }} \times\left(N_{\text {Maxtler }}-1\right)
$$

\subsubsection{Crossover probability}

Crossover probability must be defined between 0 and 1 . A low value increases the exploitation of available design points (parents), while a high value promotes the exploration of new design though the generation of offspring. A typical value of crossover probability of 0.90 [68] is used here.

\subsubsection{Mutation probability}

Mutation probability must be defined between 0 and 1 . A larger value increases the randomness of the algorithm until it becomes a basic random search for a value of 1 . A typical value of mutation probability of 0.01 [68] is used here.

\subsection{Flowchart of the optimisation model}

Fig. 9 depicts the flowchart of the structural optimisation model of OWT support structures, which combines the parametric FEA model (presented in Section 4) and the GA model (presented in Section 5). Each step of the flowchart in Fig. 9 is detailed as follows.

1) Define objectives, variables and constraints: The first step is to define the optimisation objectives, problem constraints and design variables.

2) Initialise population: A first initial population of points is generated through a random sampling process. This step is of paramount importance to initially explore the design space, providing a large genetic diversity and orienting the rest of the process in the best area of design points. A larger initial population increases the chance of finding the design point closest to the best solution.

3) Generate a new population: Based on the three evolution mechanisms described before, pools of parents are selected, children are formed from crossover, and mutation is applied to finally define the new generation.

4) Design point update: In this step, the new population of design points is passed to the parametric FEA model to update the FEA results, and then the updated FEA results are feedback to GA to update the fitness of design points.

5) Convergence validation: Since mutation continuously introduces new design points, a convergence criterion assesses when the population of design points is considered sufficiently homogeneous.

6) Stopping criterion validation: in this step, an appropriate stopping criterion is defined to stop the optimisation process after a given number of iterations.

The above Steps 3 to 6 are continuously repeated until the optimisation has converged or the stopping criterion has been met. 


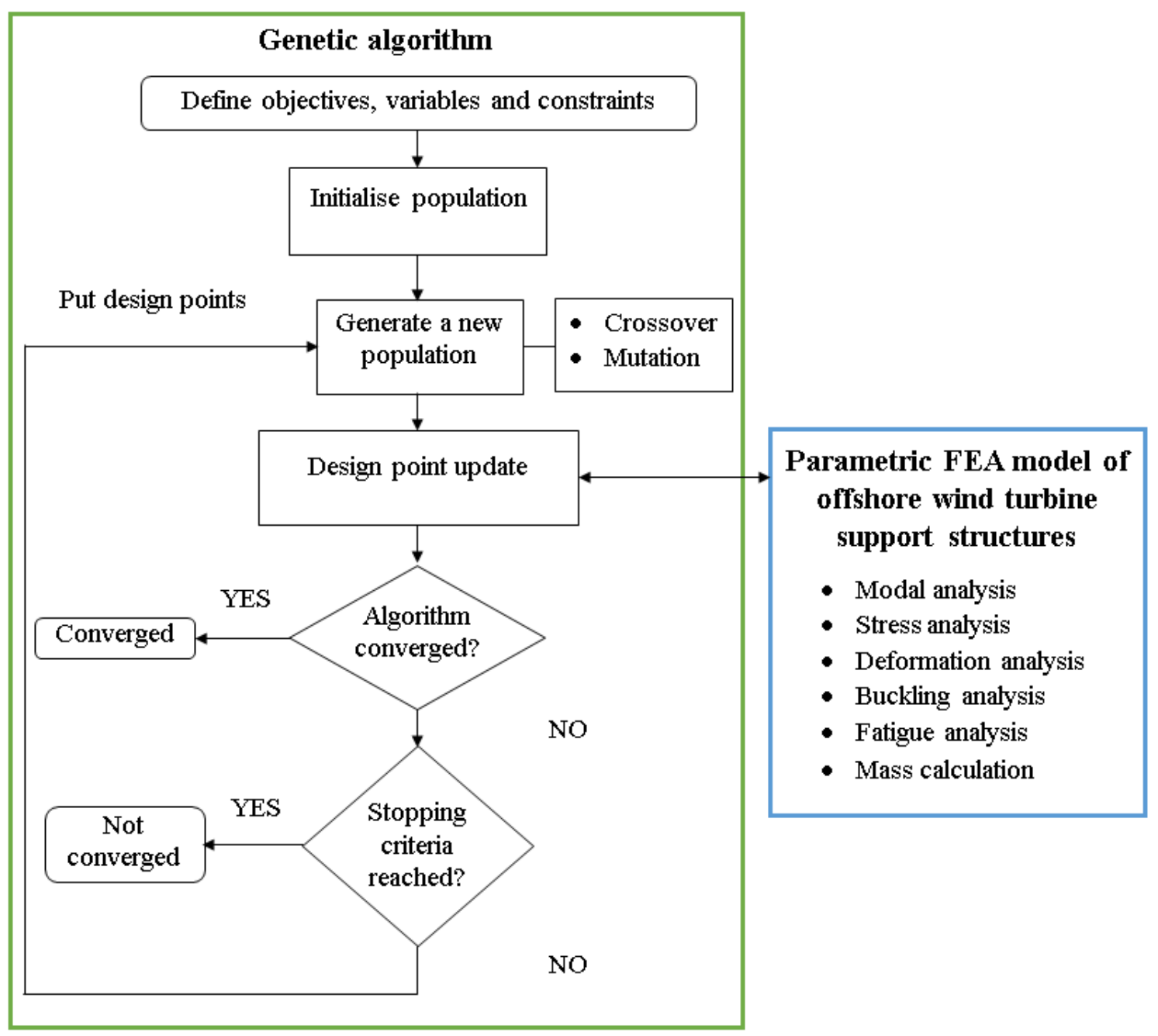

Figure 9. Flowchart of the structural optimisation model

\section{Results and discussions}

\subsection{Objective function}

The evolution of the mass objective function, along with the initial population of points is presented in Fig. 10. Seeking a global optimum forces the GA to widely explore the search space, which explains why only $14.5 \%$ of the initial points are feasible and justifies the choice of a larger initial number of points. The very first steps of the optimisation are focussed on exploration during which a wide diversity of designs is assessed and the minimum mass quickly decreases. Then, a phase of exploitation follows, in which the entire population converges until it reaches a unique design. It takes 21 generations to converge, and the best design with a mass of 742 Tonnes is obtained after 1,114 evaluations. The optimal support structure design is thus $19.8 \%$ lighter than initial design (924 Tonnes), which corresponds to an absolute mass saving of 182 Tonnes. 


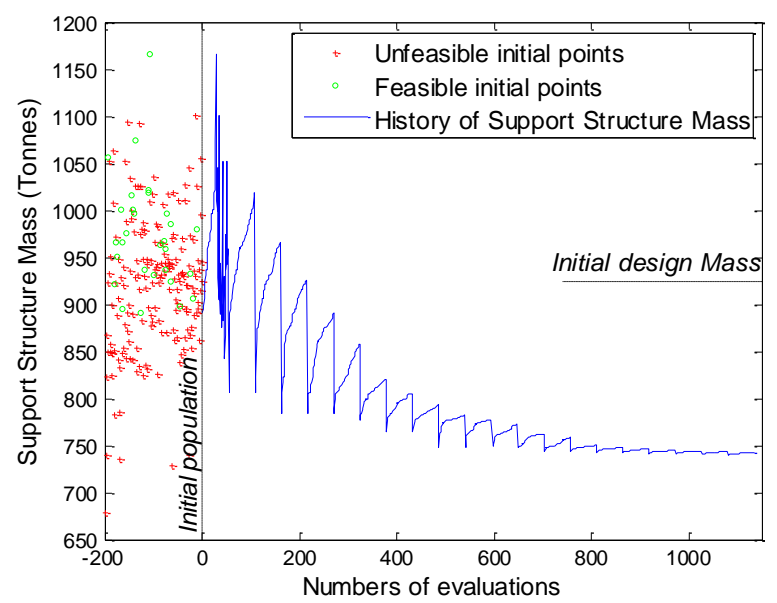

Figure 10. History of support structure mass

Details of mass saving in Table 13 show that the largest contribution (84.9\%) comes from the monopile with a global mass reduction of $27.0 \%$, while mass reduction of the tower is $10.0 \%$. Actually, this appears logical since the NREL 5MW OWT is developed based on real machines that have been designed through years of experience, while the OC3 monopile design is far less sophisticated. Influence and interest in an integrated approach has arisen by seeing that the optimal solution is not the one in which every component is optimised, i.e. here the transition piece increases its mass by $1.0 \%$.

Table 13. Detailed mass savings between initial and optimised design

\begin{tabular}{lllll}
\hline Mass (Tonnes) & Initial & Optimised & \% Diff & \% of total savings \\
\hline Tower & 240.0 & 215.9 & -10.0 & 13.2 \\
Transition piece & 61.6 & 62.2 & 1.0 & -0.3 \\
Grout & 45.4 & 41.2 & -9.3 & 2.3 \\
Monopile - Sub-Structure & 232.7 & 168.0 & -27.8 & 35.4 \\
Monopile - Foundation & 344.7 & 254.3 & -26.2 & 49.5 \\
\hline \hline Whole support structure & 924.4 & 741.6 & -19.8 & \\
\hline \hline
\end{tabular}

\subsection{Design constraints}

Evolutions of the design constraints are monitored and displayed in Fig. 11. It appears that the design is mainly driven by the first natural frequency and the fatigue, as being the most saturated constraints, which is in good agreement with design standards [25, 48]. Although buckling and especially maximum von Mises stress could have looked less contributory, they are highly activated during the selection of first generation points from the initial population, which is absolutely decisive for the rest of the optimisation, as observed in Fig. 12. 

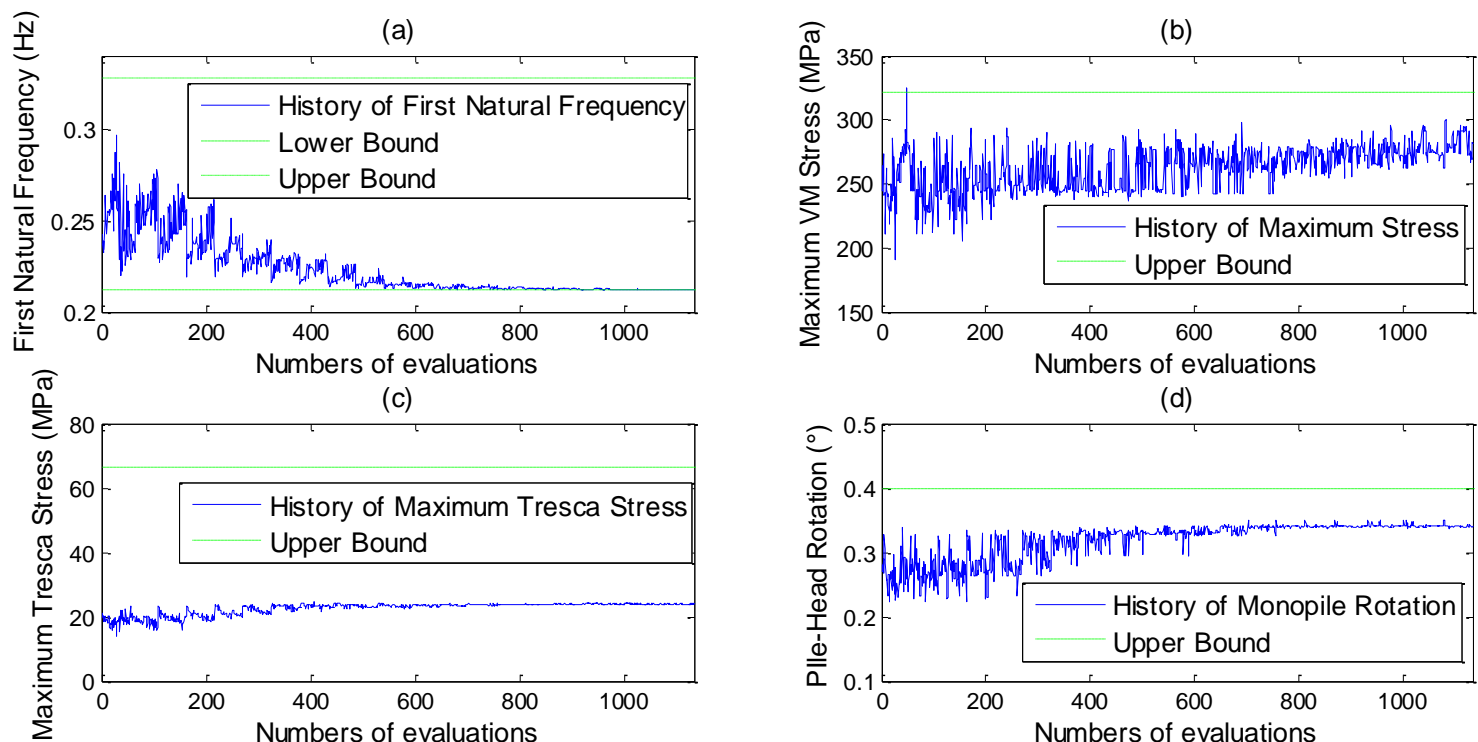

(d)

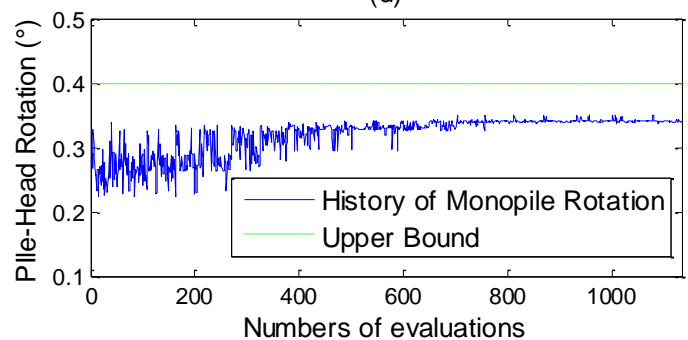

(f)
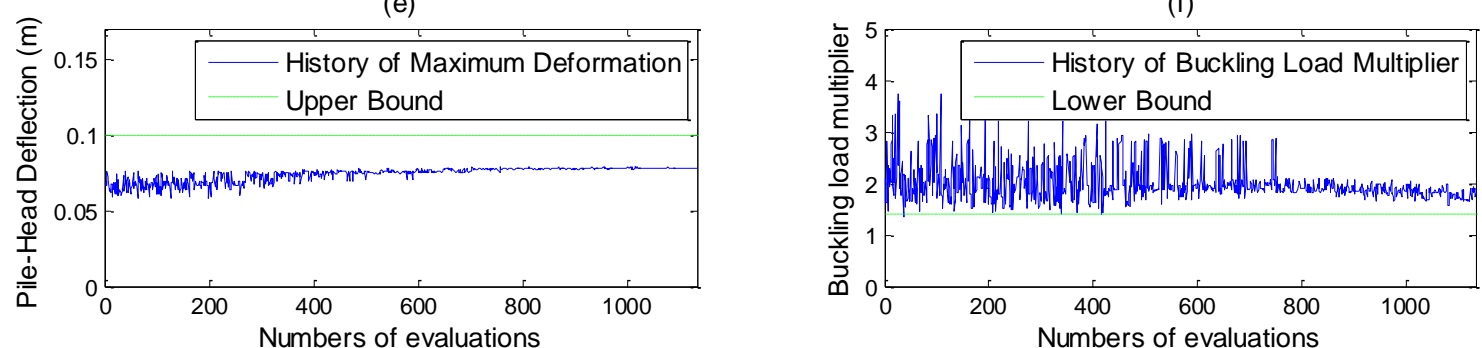

(g)

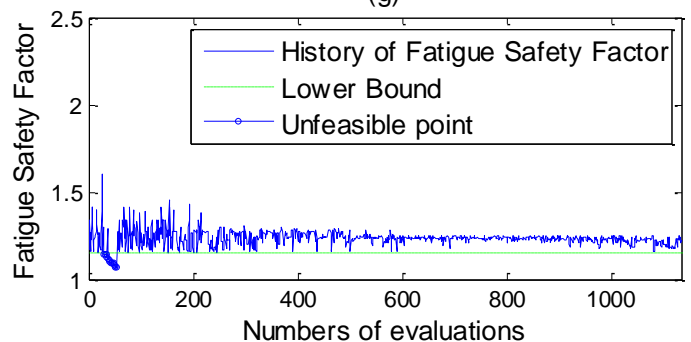

Figure 11. History of the optimisation constraint criteria: a first natural frequency, b maximum von Mises stress, c maximum Tresca stress, $\mathbf{d}$ monopile rotation, $\mathbf{e}$ maximum deformation, $\mathbf{f}$ buckling load multiplier, $\mathbf{g}$ fatigue safety ratio

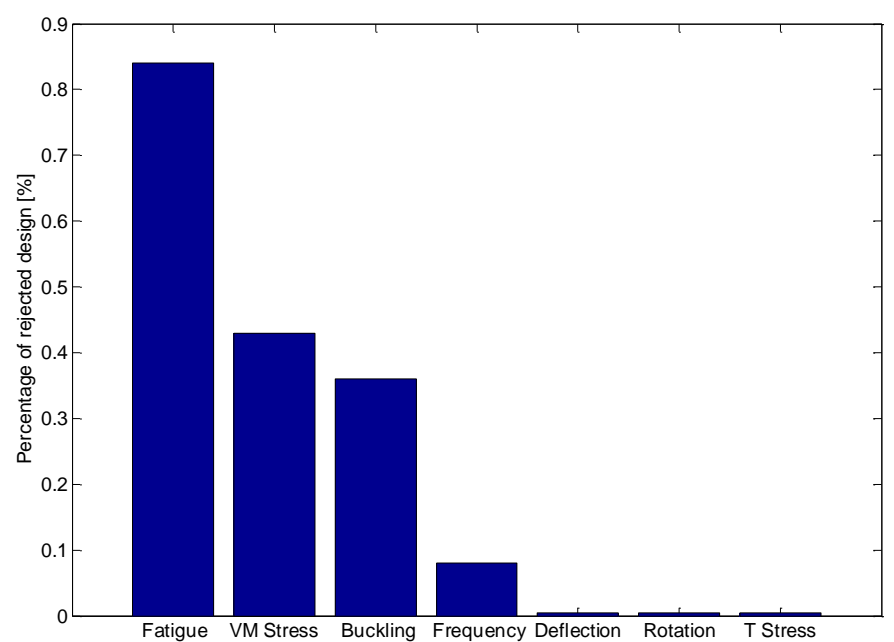

Figure 12. Contribution of each constraint in the initial design point rejection 


\subsection{Design variable}

The thickness and diameter profiles of the optimal design are compared with those of initial design, as depicted in Fig. 13 and Table 14. From Fig. 13 and Table 14 we can see that the thickness plays a major role in the mass reduction of the monopile, especially for the foundation, while the outer diameter is slightly increased. The result of foundation thickness can be justified by considering the combined stiffness of the soil and pile. Thus, at deeper soil locations, stiffness provided by the soil is higher, which means that an identical equivalent stiffness is achieved for a thinner pile. For the rest of the structure, the material quantity is increased where the stress is known to be the highest (i.e. junction of tower and transition piece). The outer diameter is significantly reduced for the non-embedded part of the support structure. Thus, it appears that both types of design variable play an important role in optimisation result.
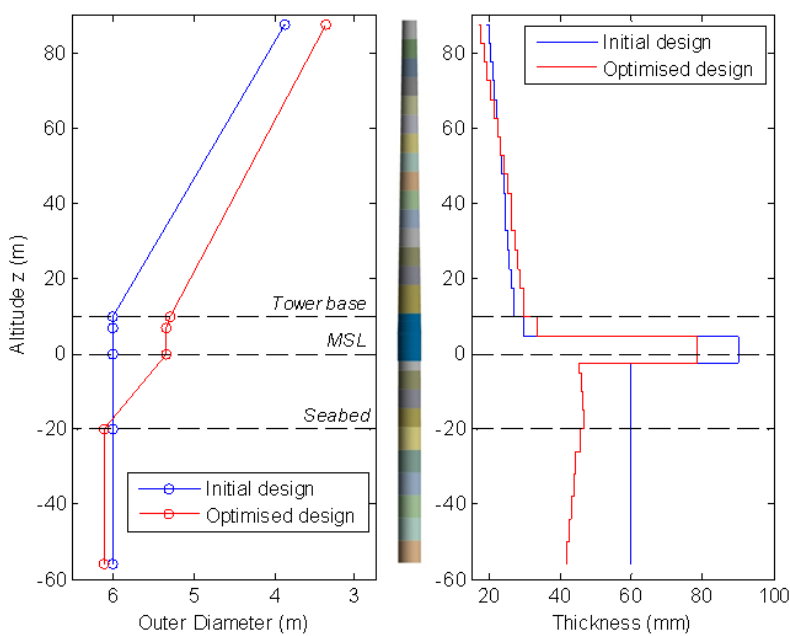

Figure 13. Comparison of initial and optimised design

Table 14. Comparison of initial and optimised design

\begin{tabular}{llll}
\hline Design variable & Initial & Optimised & Variable definition \\
\hline$x_{1}$ MonopBaseD [m] & 6.00 & 6.11 & Diameter of monopile base \\
\hline$x_{2}$ MonopTopD [m] & 6.00 & 5.34 & Diameter of monopile top \\
\hline$x_{3}$ TowerBaseD [m] & 6.00 & 5.29 & Diameter of tower base \\
\hline$x_{4}$ TowerTopD [m] & 3.87 & 3.35 & Diameter of tower top \\
\hline$x_{5}$ TowerBaseTh [m] & 0.027 & 0.030 & Thickness of tower base \\
\hline$x_{6}$ TowerInt1Th [m] & 0.025 & 0.026 & Thickness of tower Intermediate location 1 \\
\hline$x_{7}$ TowerInt2Th [m] & 0.022 & 0.021 & Thickness of tower Intermediate location 2 \\
\hline$x_{8}$ TowerTopTh [m] & 0.019 & 0.017 & Thickness of tower top \\
\hline$x_{9}$ MonopSubBaseTh [m] & 0.060 & 0.047 & Thickness of monopile substructure base \\
\hline$x_{10}$ MonopSubTopTh [m] & 0.060 & 0.045 & Thickness of monopile substructure top \\
\hline$x_{11}$ MonopFoundBaseTh [m] & 0.060 & 0.042 & Thickness of monopile foundation base \\
\hline$x_{12}$ MonopFoundTopTh [m] & 0.060 & 0.046 & Thickness of monopile foundation top \\
\hline$x_{13}$ TransPieceTh [m] & 0.030 & 0.034 & Thickness of transition piece \\
\hline
\end{tabular}




\subsection{Structural results of the optimised design}

The modal frequency, stress distribution, deformation, buckling and fatigue analysis results of the optimised solution are presented below.

\subsubsection{Modal frequencies and shapes}

Modal analysis provides the dynamics properties and resonance assessment of the structure. Fig. 14 depicts the modal shape of the first mode of the optimised support structure, and the value of first modal frequency is also presented in Fig. 14. As can be seen from Fig. 14, the first modal frequency is about $0.2123 \mathrm{~Hz}$, which is within the desired range of $0.212 \mathrm{~Hz}$ and $0.328 \mathrm{~Hz}$. The first modal frequency of optimised support structure is close to the lower bound. This is due to the fact that 1) the thickness of the support structure is reduced during the optimisation process, which results in the lower value of modal frequency; 2) the modal frequency is one of the main design drivers for the support structure.
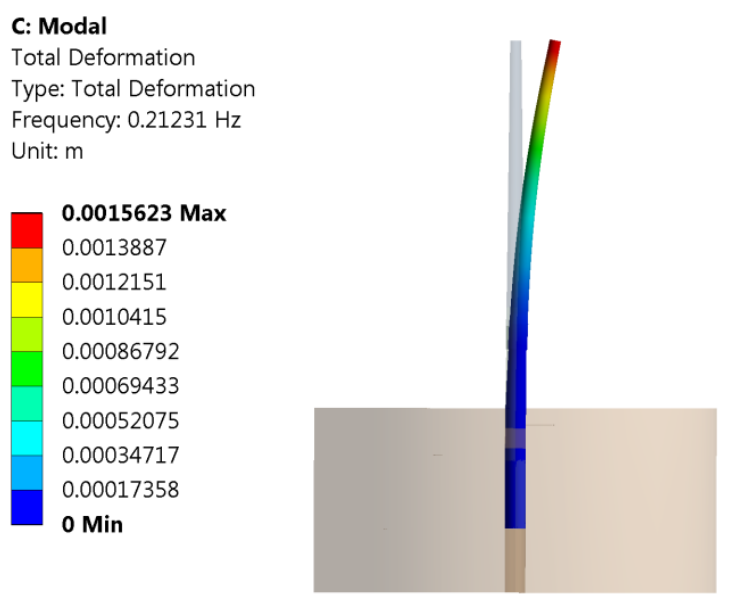

Figure 14. Modal frequency and modal shape of the first mode of support structure

\subsubsection{Stress distribution}

Stress distributions of the support structure under ultimate load case are depicted in Fig. 15. As can be seen from Fig. 15, the most stressed components are the tower and the transition piece. The maximum equivalent (von Mises) stress is equal to $288 \mathrm{MPa}$, which is $10.8 \%$ lower than the allowable value of $323 \mathrm{MPa}$. Maximum Tresca stress (see Fig. 15d) in the grout is about $24 \mathrm{MPa}$, which is $64.2 \%$ lower than the allowable value of $67 \mathrm{MPa}$. This indicates that the present support structure design is safe in terms of ultimate limit state.

As expected, the highest stress in the monopile is observed near the seabed level, with a value of $209 \mathrm{MPa}$ at the transition between loose and medium sand, i.e. where the soil becomes sufficiently stiff to make the support structure behave similarly to a cantilever beam. 


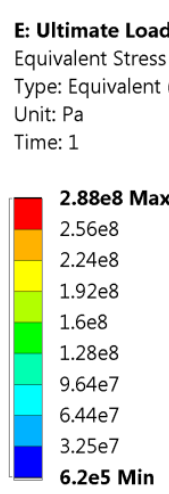

E: Ultimate Load Case

Equivalent Stress

Type: Equivalent (von-Mises) Stress - Top/Bottom

Unit: $\mathrm{Pa}$

Time: 1

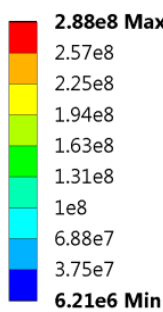

6.21e6 Min

(b)

\begin{tabular}{l} 
E: Ultimate Load Case \\
Tresca stress \\
Expression: SINT \\
Unit: Pa \\
Time: 1 \\
\\
$2.38 \mathrm{e} 7 \mathrm{Max}$ \\
$2.12 \mathrm{e} 7$ \\
$1.86 \mathrm{e} 7$ \\
$1.61 \mathrm{e} 7$ \\
$1.35 \mathrm{e} 7$ \\
$1.09 \mathrm{e} 7$ \\
$8.38 \mathrm{e} 6$ \\
$5.82 \mathrm{e} 6$ \\
$3.25 \mathrm{e} 6$ \\
$6.91 \mathrm{e} 5$ \\
\hline
\end{tabular}

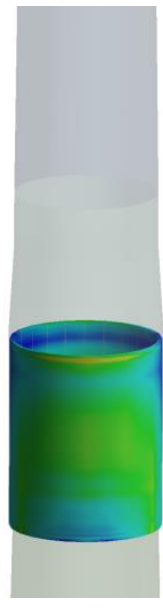

(d)

\subsubsection{Deformation}

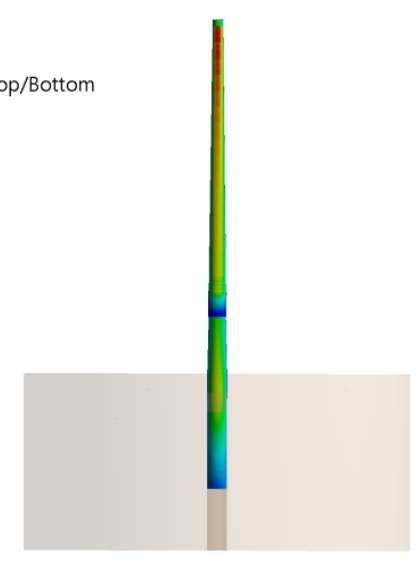

(a)
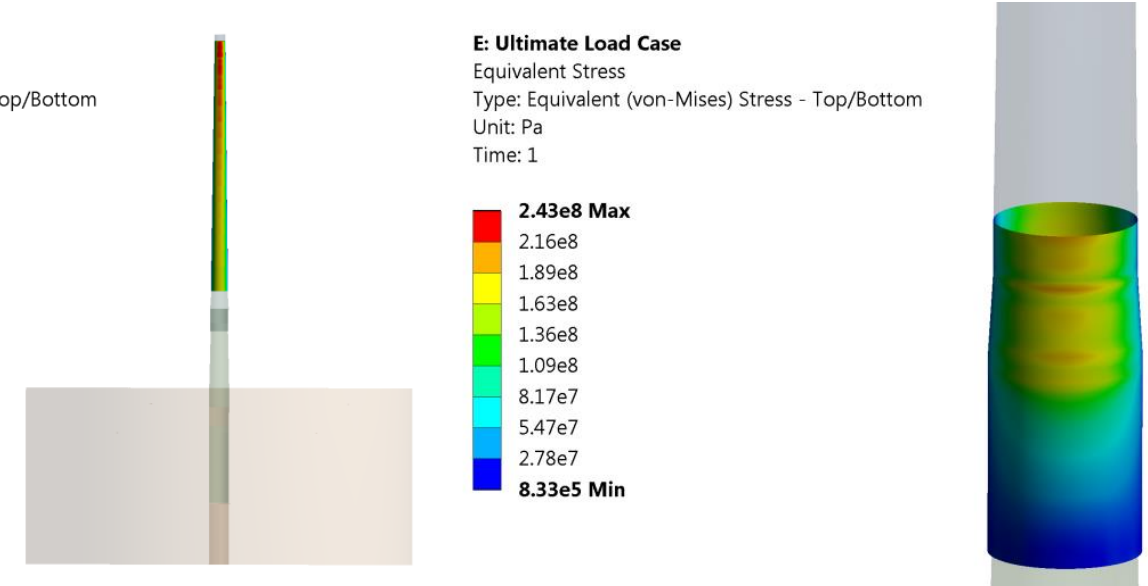

(c)

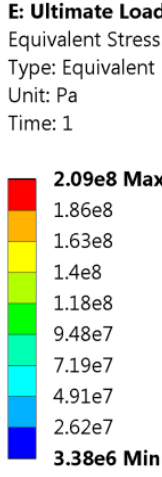

(e)

Figure 15. Stress distribution: a entire support structure, b tower, $\mathbf{c}$ transition piece, $\mathbf{d}$ grout, e monopile

Deformation fields are displayed in Fig. 16. As can be seen from Fig. 16a, the maximum deformation of the support structure is observed at the tower top, with a value of $2.87 \mathrm{~m}$. As can be seen from Fig. 16b, the maximum foundation head deflection is observed at mudline with a value of $0.078 \mathrm{~m}$, which is $22.0 \%$ lower than the allowable value of $0.1 \mathrm{~m}$. 
The deformation of the foundation head and soil induce a $0.342^{\circ}$ of rotation at the mudline, which is $14.5 \%$ lower than the allowable value of $0.4^{\circ}$. This indicates the present support structure design is unlikely to experience large deflections.

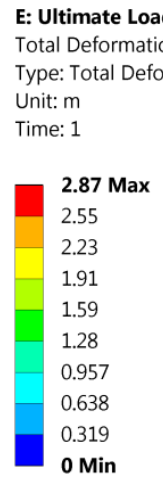

\subsubsection{Buckling}

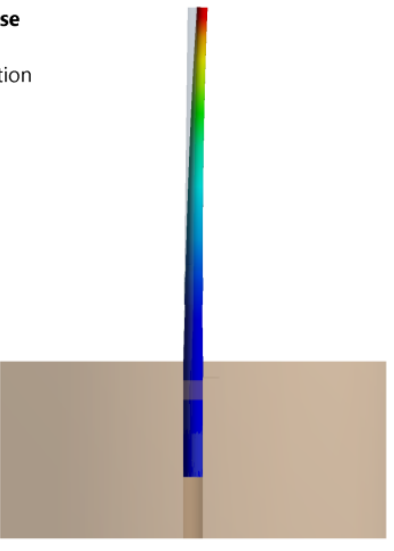

(a)
E: Ultimate Load Case

Directional Deformation

Type: Directional Deformation(X Axis)

Global Coordinate System

Time: 1

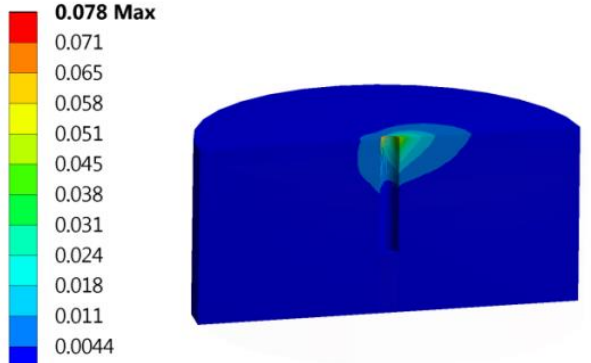

(b)

Figure 16. Deformation: a deformation of support structure, $\mathbf{b}$ section view of deformation of foundation and soil

The buckling analysis results of the OWT support structure are depicted in Fig. 17. As can be seen from Fig. 17, the buckling load multiplier is about 1.7 , which is $21.4 \%$ higher than the limit value of 1.4 . This indicates the present OWT support structure design is not likely to suffer from buckling failure.

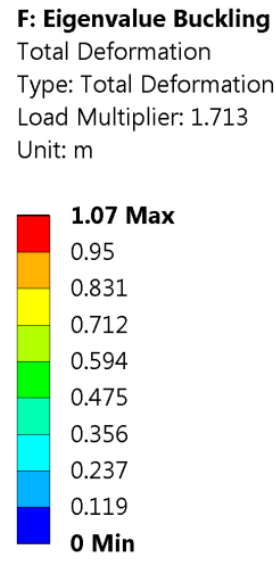

Euckling Load Multiplier: 1.713

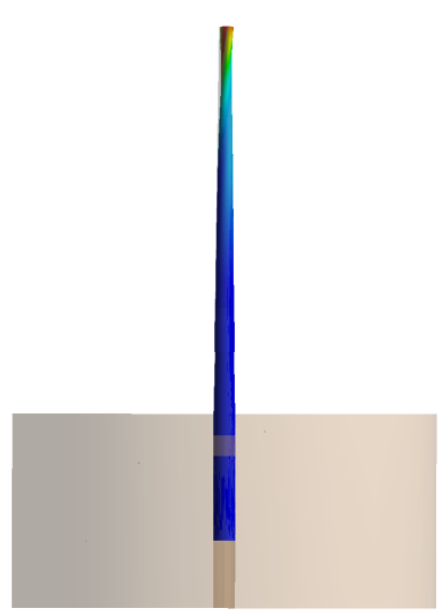

Figure 17. Buckling load multiplier and buckling mode shape of OWT support structure under ultimate load case

\subsubsection{Fatigue}

The distribution of the fatigue safety ratio of the support structure is depicted in Fig. 18. As can be seen from Fig. 18, the minimum fatigue safety ratio is about 1.2 , which is $4.3 \%$ above the criteria limit of 1.15 . This indicates the present support structure design should survive its design lifetime under fatigue loading. 


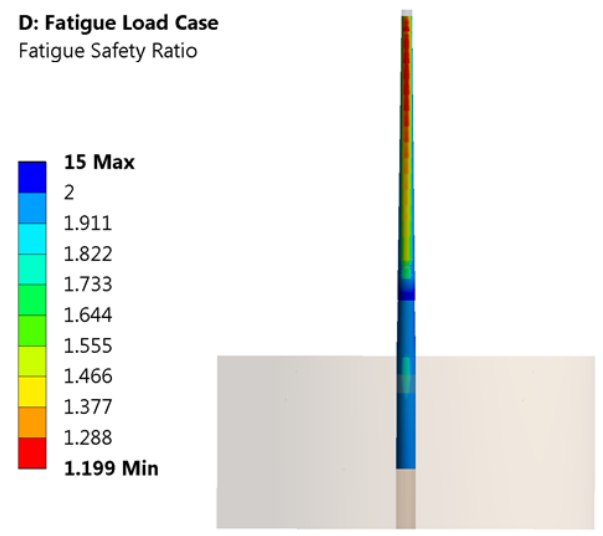

Figure 18. Fatigue safety ratio of the support structure under fatigue load case

\section{Conclusions}

In this work, an integrated structural optimisation model for OWT support structures has been developed by incorporating 1) a parametric FEA model, which describes the structural behaviour of the support structures; and 2) a GA, which searches for optimal solutions. The proposed model is an integrated optimisation model, which optimises the components of the support structure (i.e. tower, transition piece, grout and monopile) simultaneously and minimises the overall mass of the support structure with multiple design constraints. The external diameters and sectional thickness along the support structure are selected as design variables. The optimisation model takes account of six constraint conditions, i.e. vibration, stress, deformation, buckling, fatigue and design variable constraints. The model has been applied to the NREL 5MW OWT on an OC3 monopile to demonstrate its performance. The following conclusions can be drawn from the present study:

- Good agreements with reference values for modal frequencies and deflection are achieved, confirming the validity of the present parametric FEA model.

- By using the proposed optimisation model, the mass of the support structure is reduced by $19.8 \%$, which corresponds to an absolute mass of 182.7 Tonnes. This indicates the mass of the support structure can be significantly reduced by using the proposed optimisation model.

- The optimised geometry of the monopile is proved to be more sophisticated than the initial one.

- Adopting an integrated optimisation approach is an efficient way to optimise the global mass of a structure.

- Fatigue and natural frequency appeared to be the main design drivers, which is in good agreement with the recommendation from design standards. However, the remaining criteria also proved to be relevant and are activated several times during optimisation.

Additionally, the proposed optimisation model can be used for any practice of structural optimisation of OWT support structures, minimising the mass of the support structure with multi-criteria constraint conditions. The proposed optimisation framework is generic in nature and can be applied to a series of related problems, such as the structural optimisation of support structure for floating wind turbines. 


\section{Acknowledgements}

This work was supported by a grant from the Supergen Wind Hub EP/L014106/1, from the UK Engineering and Physical Sciences Research Council (EPSRC), under the Flexible Funding Scheme for Cranfield University.

\section{References}

[1] G.W.E. Council, Global wind statistics 2015, Report. Brussels, Belgium: GWEC (2016).

[2] L. Wang, X. Liu, A. Kolios, State of the art in the aeroelasticity of wind turbine blades: Aeroelastic modelling, Renewable and Sustainable Energy Reviews 64 (2016) 195-210.

[3] N. Ederer, The market value and impact of offshore wind on the electricity spot market: Evidence from Germany, Applied Energy 154 (2015) 805-814.

[4] EWEA, Wind in power - 2015 European statistics, European Wind Energy Association 2016.

[5] M.J. Kühn, Dynamics and design optimisation of offshore wind energy conversion systems, TU Delft, Delft University of Technology2001.

[6] M. Esteban, D. Leary, Current developments and future prospects of offshore wind and ocean energy, Applied Energy 90(1) (2012) 128-136.

[7] M. Arshad, B.C. O'Kelly, Offshore wind-turbine structures: a review, Proceedings of the Institution of Civil Engineers-Energy 166(4) (2013) 139-152.

[8] E. Lozano-Minguez, A.J. Kolios, F.P. Brennan, Multi-criteria assessment of offshore wind turbine support structures, Renewable Energy 36(11) (2011) 2831-2837.

[9] A. Kolios, M. Collu, A. Chahardehi, F. Brennan, M. Patel, A multi-criteria decision making method to compare support structures for offshore wind turbines, European Wind Energy Conference, Warsaw, 2010.

[10] A. Kolios, V. Mytilinou, E. Lozano-Minguez, K. Salonitis, A Comparative Study of Multiple-Criteria Decision-Making Methods under Stochastic Inputs, Energies 9(7) (2016) 566.

[11] H. Martin, G. Spano, J. Küster, M. Collu, A. Kolios, Application and extension of the TOPSIS method for the assessment of floating offshore wind turbine support structures, Ships and Offshore Structures 8(5) (2013) 477-487.

[12] J. Wilkes, J. Moccia, A. Arapogianni, M. Dragan, N. Plytas, A. Genachte, J. Guillet, P. Wilczek, The European offshore wind industry key 2015 trends and statistics, European Wind Energy Association (2016).

[13] D. Kallehave, B.W. Byrne, C.L. Thilsted, K.K. Mikkelsen, Optimization of monopiles for offshore wind turbines, Phil. Trans. R. Soc. A 373(2035) (2015) 20140100.

[14] S. Tegen, M. Hand, B. Maples, E. Lantz, P. Schwabe, A. Smith, 2013 Cost of wind energy review, Golden, Colorado, National Renewable Energy Laboratory (NREL) (2015).

[15] B. Hamilton, L. Battenberg, M. Bielecki, C. Bloch, T. Decker, L. Frantzis, J. Paidipati, A. Wickless, F. Zhao, Offshore Wind Market and Economic Analysis: Annual Market Assessment, Navigant Consulting, Inc., Burlington, MA (2013).

[16] E. Bossanyi, GH Bladed user manual, Garrad Hassan Bladed (2009).

[17] F. Petrini, S. Manenti, K. Gkoumas, F. Bontempi, Structural design and analysis of offshore wind turbines from a system point of view, Wind Engineering 34(1) (2010) 85-108.

[18] L. Wang, R. Quant, A. Kolios, Fluid structure interaction modelling of horizontal-axis wind turbine blades based on CFD and FEA, Journal of Wind Engineering and Industrial Aerodynamics 158 (2016) 11-25.

[19] L. Wang, A. Kolios, P.-L. Delafin, T. Nishino, T. Bird, Fluid Structure Interaction Modelling of A Novel 10MW Vertical-Axis Wind Turbine Rotor Based on Computational Fluid Dynamics and Finite Element Analysis, EWEA 2015 Annual Event, France, Paris (2015).

[20] K. Abdel-Rahman, M. Achmus, Finite element modelling of horizontally loaded monopile foundations for offshore wind energy converters in Germany, Proceedings of the international symposium on frontiers in offshore geotechnics. Taylor and Francis, Perth, 2005, pp. 391-396. 
[21] N. Veritas, Guidelines for design of wind turbines, Det Norske Veritas: Wind Energy Department, Ris National Laboratory2002.

[22] D.R. SM, Recommended Practice for Planning, Designing and Constructing Fixed Offshore Platforms-Working Stress Design, (2000).

[23] S. Jung, S.-R. Kim, A. Patil, Effect of monopile foundation modeling on the structural response of a 5-MW offshore wind turbine tower, Ocean Engineering 109 (2015) 479-488.

[24] A. Haiderali, G. Madabhushi, Three-dimensional finite element modelling of monopiles for offshore wind turbines, Proceedings of the world congress on advances in civil, environmental, and materials research, Seoul, 2012, pp. 3277-3295.

[25] DNVGL, DNVGL-ST-0126: Support structures for wind turbines, 2016.

[26] M. Muskulus, S. Schafhirt, Design optimization of wind turbine support structures-a review, Journal of Ocean and Wind Energy 1(1) (2014) 12-22.

[27] J.F. Herbert-Acero, O. Probst, P.-E. Réthoré, G.C. Larsen, K.K. Castillo-Villar, A review of methodological approaches for the design and optimization of wind farms, Energies 7(11) (2014) 6930-7016.

[28] K.-H. Chew, K. Tai, E. Ng, M. Muskulus, Analytical gradient-based optimization of offshore wind turbine substructures under fatigue and extreme loads, Marine Structures 47 (2016) 23-41.

[29] K.-H. Chew, K. Tai, E. Ng, M. Muskulus, Optimization of Offshore Wind Turbine Support Structures Using an Analytical Gradient-based Method, Energy Procedia 80 (2015) 100-107.

[30] A. Perelmuter, V. Yurchenko, Parametric optimization of steel shell towers of high-power wind turbines, Procedia Engineering 57 (2013) 895-905.

[31] G. Clauss, L. Birk, Hydrodynamic shape optimization of large offshore structures, Applied Ocean Research 18(4) (1996) 157-171.

[32] M. Saka, O. Hasançebi, Z. Geem, Metaheuristics in structural optimization and discussions on harmony search algorithm, Swarm and Evolutionary Computation 28 (2016) 88-97.

[33] D.E. Golberg, Genetic algorithms in search, optimization, and machine learning, Addion wesley 1989 (1989) 102.

[34] H. Yang, Z. Wei, L. Chengzhi, Optimal design and techno-economic analysis of a hybrid solar-wind power generation system, Applied Energy 86(2) (2009) 163-169.

[35] X. Gao, H. Yang, L. Lu, Optimization of wind turbine layout position in a wind farm using a newly-developed twodimensional wake model, Applied Energy 174 (2016) 192-200.

[36] L. Wang, A. Kolios, T. Nishino, P.-L. Delafin, T. Bird, Structural optimisation of vertical-axis wind turbine composite blades based on finite element analysis and genetic algorithm, Composite Structures (2016).

[37] S. Yoshida, Wind turbine tower optimization method using a genetic algorithm, Wind Engineering 30(6) (2006) 453-469.

[38] M. Martinez-Luengo, A. Kolios, L. Wang, Structural health monitoring of offshore wind turbines: A review through the Statistical Pattern Recognition Paradigm, Renewable and Sustainable Energy Reviews 64 (2016) 91-105.

[39] A. Chehouri, R. Younes, A. Ilinca, J. Perron, Review of performance optimization techniques applied to wind turbines, Applied Energy 142 (2015) 361-388.

[40] L. Arany, S. Bhattacharya, J. Macdonald, S. Hogan, Design of monopiles for offshore wind turbines in 10 steps, Soil Dynamics and Earthquake Engineering 92 (2017) 126-152.

[41] H. Long, G. Moe, T. Fischer, Lattice towers for bottom-fixed offshore wind turbines in the ultimate limit state: variation of some geometric parameters, Journal of Offshore Mechanics and Arctic Engineering 134(2) (2012) 021202.

[42] Y.-S. Lee, J.A. González, J.H. Lee, Y.I. Kim, K. Park, S. Han, Structural topology optimization of the transition piece for an offshore wind turbine with jacket foundation, Renewable Energy 85 (2016) 1214-1225.

[43] T. Ashuri, Beyond classical upscaling: integrated aeroservoelastic design and optimization of large offshore wind turbines, TU Delft, Delft University of Technology2012.

[44] J. Jonkman, S. Butterfield, W. Musial, G. Scott, Definition of a 5-MW reference wind turbine for offshore system development, National Renewable Energy Laboratory, Golden, CO, Technical Report No. NREL/TP-500-38060 (2009).

[45] J. Jonkman, W. Musial, Offshore code comparison collaboration (OC3) for IEA task 23 offshore wind technology and deployment, Contract 303 (2010) 275-3000. 
890 [46] M.S. Andersen, P. Petersen, Structural design of grouted connection in offshore steel monopile foundations, Global 891 Windpower Conference, 2004.

892 [47] IEC, IEC 61400-1: Wind turbines part 1: Design requirements, 2005.

893 [48] I.E. Commission, IEC 61400-3: 2009 Wind Turbines-Part 3: Design Requirements for Offshore Wind Turbines, Geneva, 894 Switzerland (2009).

895 [49] DNV, DNV-OS-J101: Offshore standard for design of offshore wind turbine structures, 2014.

896 [50] D. DNV, DNV-RP-C205: Environmental conditions and environmental loads, Norw ay: DetNorskeVeritas (2010).

[51] M.W. LaNier, LWST Phase I Project Conceptual Design Study: Evaluation of Design and Construction Approaches for Economical Hybrid Steel/Concrete Wind Turbine Towers; June 28, 2002--July 31, 2004, National Renewable Energy Lab., Golden, CO (US), 2005.

[52] D. Malcolm, A. Hansen, WindPACT turbine rotor design study, National Renewable Energy Laboratory, Golden, CO 5 (2002).

[53] G. Freebury, W.D. Musial, Determining equivalent damage loading for full-scale wind turbine blade fatigue tests, National Renewable Energy Laboratory2000.

[54] M.W. Dingemans, Water wave propagation over uneven bottoms, TU Delft, Delft University of Technology, 1994.

[55] S.K. Chakrabarti, Ocean Environment, Handbook of Offshore Engineering, Elsevier (2005).

[56] P. Schaumann, C. Böker, A. Bechtel, S. Lochte-Holtgreven, Support structures of wind energy converters, Environmental Wind Engineering and Design of Wind Energy Structures, Springer2011, pp. 191-253.

[57] GL, Rule for Regulation IV-Non marine technology, Part 2 Offshore Wind Energy. Regulations for the Certification of offshore wind energy conversion system, Hamburg, 1995.

[58] Y.-S. Lee, B.-L. Choi, J.H. Lee, S.Y. Kim, S. Han, Reliability-based design optimization of monopile transition piece for offshore wind turbine system, Renewable Energy 71 (2014) 729-741.

[59] Densit, Ducorit Data Sheet - Ultra High performance grout, 2013.

[60] D.C. Drucker, W. Prager, Soil mechanics and plastic analysis or limit design, Quarterly of applied mathematics 10(2) (1952) 157-165.

[61] O. R, The Hardening Soil Model: A Practical Guidebook, 2010.

[62] ANSYS, ANSYS help documentation, 2015.

[63] R.R. Damiani, H. Song, A.N. Robertson, J.M. Jonkman, Assessing the importance of nonlinearities in the development of a substructure model for the wind turbine CAE tool FAST, ASME 2013 32nd International Conference on Ocean, Offshore and Arctic Engineering, American Society of Mechanical Engineers, 2013, pp. V008T09A093-V008T09A093.

[64] J. Arora, Introduction to optimum design, Academic Press2012.

[65] H. Adelman, Experimental validation of the utility of structural optimization, Structural optimization 5(1-2) (1992) 3-11.

[66] S. Bhattacharya, Challenges in design of foundations for offshore wind turbines, Engineering \& Technology Reference 1(1) (2014).

[67] G. Lloyd, G. Hamburg, Guideline for the certification of wind turbines, Edition, 2010.

[68] R.L. Haupt, S.E. Haupt, Practical genetic algorithms, John Wiley \& Sons2004. 